

\section{DISCLAIMER}

This report was prepared as an account of work sponsored by an agency of the United States Government. Neither the United States Government nor any agency Thereof, nor any of their employees, makes any warranty, express or implied, or assumes any legal liability or responsibility for the accuracy, completeness, or usefulness of any information, apparatus, product, or process disclosed, or represents that its use would not infringe privately owned rights. Reference herein to any specific commercial product, process, or service by trade name, trademark, manufacturer, or otherwise does not necessarily constitute or imply its endorsement, recommendation, or favoring by the United States Government or any agency thereof. The views and opinions of authors expressed herein do not necessarily state or reflect those of the United States Government or any agency thereof. 


\section{DISCLAIMER}

Portions of this document may be illegible in electronic image products. Images are produced from the best available original document. 


\section{ENERGY SYSTEMS DIVISION}

Energy Systems Division was established by Carrier Corporation to assist in alleviating the national and international energy shortage through energy conservation. The division consists of:

Resource Recovery-Energy Systems Division will promote complete, integrated systems for transforming solid waste into valuable resources including energy. It will aid governmental agencies, municipalities, institutions and private companies in the acquisition of resource recovery systems which meet their requirements.

Solar Energy - Energy Systems Division will provide complete solar systems to supplement, or reduce the need for fossil fuel in the air conditioning of buildings. Air conditioning consists of heating, cooling, ventilation and humidification of the air circulating within a building complex. Carrier has developed a solar system for the "Carrier Energy Optimized Solar House" in Naples, Florida.

Energy Conservation-Energy Systems Division has developed automated technology and programs for monitoring and controlling the air conditioning systems of major buildings to optimize the use of energy. Working in conjunction with other technologically advanced companies, buildings sub-systems are under development for incorporation in existing as wcll as ncw construction of energy optimized buildings.

Carrier Energy Systems Division

Carrier Corporation

Carrier Tower

P. O. Box 1000

Syracuse, New York 13201 
CANDIDATE CHEMICAL SYSTEMS FOR AIR COOLED, SOLAR POWERED, ABSORPTION AIR CONDITIONER DESIGN

PART II - SOLID ABSORBENTS, HIGH LATENT HEAT REFRIGERANTS

PREPARED BY:

DR. WENDELL J. BIERMANN

PROJECT MANAGER

FOR :

$69^{54}$

ENERGY SYSTEMS DIVISION $q^{5^{\circ}} /$

CARRIER CORPORATION

P.0. BOX 4800

SYRACUSE, NEW YORK 13221

APRIL 1978

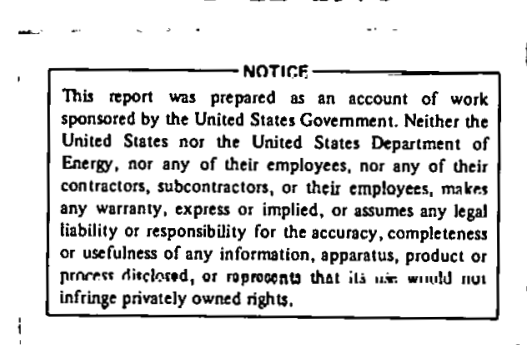

This report is submitted as one portion of the work agreed upon in Letter Contract EG-77-C-03-1587 (SAC 2) between the Department of Energy and Energy Systems Divfsion, Carrier Corporation. 


\section{SUMMARY}

This report summarizes work done in attempting to qualify absorption refrigeration systems based on refrigerants with intermediate latent heats of vaporization. In practice, these comprise methanol, ammonia and methylamine. A wide variety of organic substances, salts and mixtures were evaluated in as systematic a manner as possible.

Several systems of interest were described:

1. $\mathrm{LIClO}_{3}-\mathrm{LIBr}-\mathrm{H}_{2} \mathrm{O}$. A good "back up" system to our first cholce of an antifreeze additive system, thermodynamically promising but subject to some inconvenient materials limitations.

2. $\mathrm{LiBr} / \mathrm{ZnBr}_{2}$ - Methanol. Thermodynamically promising but requires additional kinetic qualification.

3. LiCNS - Ammonia/Methylamine with various other third components. Chemical stability does not appear to be adequate for a long lived system. 


\section{TABLE OF CONTENTS}

LIST OF FIGURES

Page

LIST OF TABLES

ii1

$1-0$

INTRODUCTION

v

$1-1$

SOME THEORETICAL CONSIDERATIONS

$1-2$

LITHIUM BROMIDE-WATER

2-0

EXPERIMENTAL RESULTS, SALTS AND WATER

2-1

SINGLE SALTS, SOLUTION VAPOR PRESSURES

2-1.i OTHER SALTS AND SALT-LIKE MATERIALS

$2-2$

MIXTURES OF SALTS

$2-2.1$

LITHIUM CHLORATE/LITHIUM BROMIDE-WATER

$2-2.2$

LITHIUM ACETATE-LITHIUM CHLORIDE

$2-2.3$

OTHER LITHIUM SALT MIXTURES

$2-3$

LITHIUM SALTS, WITH NON-LITHIUM SALTS

33

$2-3.1$

ZINC HALIDES

3-0

REFRIGERANTS OTHER THAN WATER

3-1

METHYL ALCOHOL - LITHIUM BROMIDE

41

3-2

AMMONIA AND METHYLAMINE AS REFRIGERANTS

41.

$3-2.1$

AMMONIA/METHYLAMINE WITH ORGANIC ABSORBENTS

44

3-2.2 INORGANIC SALTS AS ABSORBENTS FOR METHYLAMINE

46

$3-2$. 3

TERNARY REFRIGERANT-ABSORBENT COMBINATIONS

51

3-2.3.1 TWO INORGANIC SALTS

59

3-2.3.2. WITH TWO ORGANIC COMPOUNDS

3-2.3.3 INORGANIC SALTS AÑD ORGANIC SOLVENTS

3-2.3.3.1 SOLVENT EFFECT

60

3-2.3.3.2 CONCENTRATION EFFECT

61

3-2.3.3.3 ANIONIC EFFECT

6.4

3-3

METHYLAMINE/AMMONIA, CONCLUSIONS

64

4-0

CONCLUSIONS AND RECOMMENDATIONS

67 


\section{LIST OF FIGURES}

Figure

Number

Description

Page

1

2

EQUILIBRIUM CHART FOR AQUEOUS LITHIUM BROMIDE SOLUTIONS

8

VAPOR PRESSURES OF SEVERAL VERY SOLUBLE LITHIUM SALTS - SOLUTIONS SATURATED AT $20^{\circ} \mathrm{C}$

VAPOR PRESSURES OF SEVERAL VERY SOLUBLE LITHIUM SALTS - SOLUTION SATURATED AT $20^{\circ} \mathrm{C}$

DUHRING PLOT FOR THE SYSTEM LITHIUM CHLORATE - WATER

DUHRING PLOT FOR LITHIUM IODIDE/WATER SOLUTION.

DUHRING CURVES' FOR THE SYSTEM SODIUM_HYDROXIDE-WATER

SOLUBILITY OF SODIUM HYDROXIDE IN WATER

SATURATION TEMPERATURE FOR THE SYSTEM $\mathrm{LIBr} / \mathrm{LiClO}{ }_{3}-\mathrm{H}_{2} \mathrm{O}$ AS A FUNCTION OF MOLE FRACTION LIBr IN THE SOLUTE

DUHRING PLOT FOR THE SYSTEM L1Br/L 1 ClO $3-\mathrm{H}_{2} \mathrm{O}$ BASED ON CARRIER RESEARCH DIVISION DATA

DIFFERENTIAL HEAT OF DILUTION OF $\mathrm{L}_{1} \mathrm{C} 1 \mathrm{O}_{3} /$ LIBr- $\mathrm{H}_{2} \mathrm{O}$ SOLUTIONS BASED ON DUHRING 3 DATA 25 SPECIFIC HEATS OF $\mathrm{LIClO}_{3} / \mathrm{LHBr}$ SOLUTIONS . . . . 26

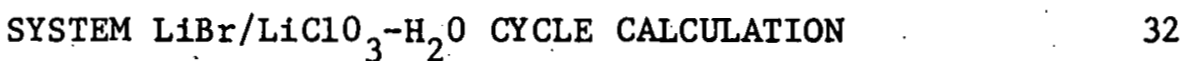
VAPOR PRESSURES OF VARIOUS MIXTURES OF LITHIUM CHLORIDE-LITHIUM ACETATE, SATURATED AT $20^{\circ} \mathrm{C}$, MEASURED AT $60^{\circ} \mathrm{C}$

VAPOR TREGSURES OF SEVERAL LITHIUM SALT MIXTURES SATURATED AT $20^{\circ} \mathrm{C}$, VAPOR PRESSURES AT $60^{\circ} \mathrm{C} .35$ DUHRING PLOTS OF LITHIUM BROMIDE-METHANOL

DUHRING PLOTS OF LITHIUM BROMIDE/ZINC BROMIDE (MOLE RATIO 2:1) IN METHANOL

DUHRING PLOTS FOR AMMONIA NAD METHYLAMTNE DISSOLVED IN WATER

TRANSITIONAL METAL THIOCYANATES IN METHYLAMINE .54

SODIUM THIOCYANATE IN METHYLAMINE $56^{\circ}$

DUHRING PLOTS FOR THE SYSTEM LITHIUM THIOCYANATEMETHYLAMINE

DUHRING PLOTS FOR THE SYSTEM LITHIUM THIOCYANATEAMMONLÁ 


\section{$-1 v-$ \\ LIST OF FIGURES (cont'd.)}

F1gure Number

22

23

24
Description

Page

DUHRING PLOT FOR THE SYSTEM (37.5\% LITHIUM

THIOCYANATE AND $62.5 \%$ TETRAMETHYLENE

GLYCOL DIMETHYL - ETHER) . WITH METHYLAMINE

62

RAOULT'S LAW FOR THE SYSTEM LITHIUM

THIOCYANATE-METHYLAMINE WITH VARIOUS

THIRD COMPONENTS

63

EFFECTS OF CONCENTRATION OF THIRD COMPONENT

65 


\section{LIST OF TABLES}

\begin{tabular}{|c|c|c|}
\hline No. & Description & Page \\
\hline I & NUMERICAL DATA FOR MIXED SALTS & 14 \\
\hline II & PROPERTIES OF $\mathrm{LIClO}_{3} / \mathrm{LiBr} / \mathrm{H}_{2} \mathrm{O}$ & 27 \\
\hline III & $\begin{array}{l}\text { EFFECT O N VAPOR PRESSURE LOWERING, ADDITION OF } \\
\text { LIOAC to LIC1 }\end{array}$ & 33 \\
\hline IV & SOLUBILITY/DEW POINTS ZINC AND CALCIUM CHLORIDES & 39 \\
\hline V & ABSORBENTS-PHENOLS, REFRIGERANT-CH $3 \mathrm{NH}_{2}$ & 48 \\
\hline VI & $\begin{array}{l}\text { ABSORBENTS-ORGANIC ESTERS WITH ACTIVE HYDROGEN } \\
\text { REFRIGERANT-CH }{ }_{3} \mathrm{NH}_{2}\end{array}$ & 49 \\
\hline VII & $\begin{array}{l}\text { ABSORBENTS-POLYHYDROXY COMPOUNDS } \\
\text { REFRIGERANT-CH }{ }_{3} \mathrm{NH}_{2}\end{array}$ & 50 \\
\hline VIII & METHYLAMINE AND HEAVY METAL THIOCYANATES & 52 \\
\hline IX & METHYLAMINE AND ALKALI METAL THIOCYANATES & 53 \\
\hline
\end{tabular}




\section{1-0 INTRODUCTION}

In the first report of this serles, the conclusion was reached that the development of solar driven absorption chillers with air heat. refection would have an increased likelihood of technical and economtc success if high latent heat refrigerants were used. Among those which should have high priority of consideration would be water, methanol and the lower molecular welght derivatives of ammonia. The few other high latent heat fluids avallable can generally be eliminated on the basis of corrosion, excessive toxicity or chemical reactivity.

\section{1-1 SOME THEORETICAL CONSIDERATIONS}

Absorption refrigeration is based on the fact that the vapor pressure of a volatile liquid, the refrigerant, can be reduced through appropriate use of a second substance, the absorbent. Most commonly this is through the formation of a solution between the volatile refrigerant and a much less volatile absorbent. Practical operating conditions dictate that the solution must show a partial pressure of refrigerant over the absorbentrefrigerant solution which is substantially less than would be predicted by Raoult's Law. Such "negative deviations from Raoult's Law" are explained in terms of forces between the absorbent and refirigerant molecules. If these forces are negligible, Raoult's Law is obeyed and as the magnitude of the forces increases the negative deviation becomes greater. In the 11miting case these forces become sufficlently large to be recognized unambiguously as chemical bonds (as would occur if boron trifluoride were absorbed by an ether). In those systems of absorbent-refrigerant which deviate sufficiently from Raoult's Law to be of practical interest, the forces are generally sufficiently high to lead to interaction energles of a few kilojoules per gram-mole, In which case it is customary to describe the interaction as chemical bond formation. The strength of the chemical bond may be taken as a measure of the deviation from Raoult's Law. Thus, the absorption of a refrigerant can be described by means of a simple chemlcal reaction:

$$
n R+A=R_{n} A
$$


In principle, at least, the vapor pressure of refrlgerant can be fixed at any desired value by selection of an absorbent with appropriate bond energy to the refrigerant.

Practical systems have thus far included only refrigerants with a high dipole moment (water and ammonia) and absorbents which interact with these dipoles by virtue of their own dipole moment (water) or by possession of an electrostat1c charge (hydrogen ion, hydroxyl ion, metallic cations). Solld absorbents are customarily used as strong solutions of the solid in the refrigerant in order to obviate mechanical and heat exchange difficulties which would occur in circulating a solid absorbent through an absorption cycle.

In the present state of the art, the most satisfactory system for absorption refrigeration has been the use of water as refrigerant and a strong aqueous solution of lithium chloride or lithium bromide as the absorbent. These solutions have several properties which restrict their usefulness, principally the fact that the absorber solution must be kept relatively cool in order that the vapor pressure of refrigerant over the solution be low enough to permit practical operation.

When a refrigerant, such as water, is absorbed by an ionic absorbent, the strength of the resultant bond is determined primarily by the total dipole moment of the refrigerant molecule and the lonlc potential (ratio of charge: of Ion to radius of ion), the bond strength increasing with both these quantities and hence glving larger devlations from Raoult!s Law. Each Iontc spectes can associate only with a small, Integral number of refrigerant molecules (called the "coordination number") which will be arranged about the fon in a fixed geometric pattern. If the ratio of refrigerant molecules to absorbent ions present exceeds the coordination number, interaction between the two is still possible but the forces are much lower, as seen from the increase in vapor pressure over the absorbent solution. 
A popular misconception is that all bonds formed between refrigerant and absorbent, within the limt of the coordination number, are of equal energy, in effect predicting that the vapor pressure of a refrigerant-absorbent solution cannot be reduced significantly by further increase in concentration of absorbent once the molar ratio of refrigerant to absorbent has decreased to the coordination number. There exist two well established theoretical methods which belie this assumption, but they need not be developed here.

It has sometimes been stated that no better absorbent for water than lithium bromide can be found. This is predicated on the lithium ion having the highest Ionic potential of any cation which has not been rejected for some practical consideration such as toxlctity, corrosion or low solubility. The prediction also implicitly includes the equal bond energles assumption in that the ratio of water molecules to lithium lons in a solution saturated at room temperature is just under four, the anticipated coordination number for the electronic configuration of lithium.

By rejecting this second postulate, there is opened the possibility of finding an absorbent superior to lithium bromide (for water, at least) by looking among those lithium salts whose solubilities are at least equal to the solubility of lithium bromide. It should be noted in passing that the numerical solubility scale, to be significant in terms of the preceding arguments, must be a measure of the relative number of moles of solvent and solute. The scale generally most convenient for this purpose is the molal scale, the number of gram formula welghts per kllogram of solvent. The familiar percentage scale of solubllity is not simply related to this mole ratio.

F1ve very soluble lithium salts are:

$\begin{array}{lcc} & \begin{array}{c}\text { Solubility }\left(20^{\circ} \mathrm{C}\right) \\ \text { Weight, } \%\end{array} \\ \text { Lithium Chlorate } & \frac{\text { Molal }}{82.0} & 50.2 \\ \text { Lithium Nitrite } & 50.9 & 29.6 \\ \text { Lithium Chloride } & 45.8 & 19.9 \\ \text { Lithium Thiocyanate } & 54.6 & 18.5 \\ \text { Lithium Bromide } & 61.0 & 18.0\end{array}$


The "state of the art" prediction would be that all five would have similar vapor pressures since each solution contains fewer than four moles of water per formula weight of 1ithium salt. The "new" approach outlined above predicts that the above arrangement is in the order of increasing vapor pressure with 1ithium bromide solution having the highest vapor pressure of the set. Experimentally we find the order of vapor pressure to be:

$$
\mathrm{LIBr} \approx \mathrm{LIClO}_{3}<\mathrm{LICl}<\mathrm{LICNS}<\mathrm{LINO}_{2}
$$

which is not in agreement with either prediction.

It was from this evidence that a concept was deduced which does not seem to have previously been considered in the art; namely, that the effectiveness of an absorbent is determined, in part, by its degree of dissociation in solution. The association of ions such as nitrite, chlorate and thiocyanate, through their non-bonding electron pairs, to cations of high ionic potential, such as the lithium ion, is consistent with our general experience with chemical bond formation between fons in solution. This assoclation, involving partial transfer of electrons through which the bond Is formed, has the net effect of lessening the effective charge on the lithium fon and thus weakening the ifthium-water bonds to which we attribute the marked reduction in water vapor pressure over lithlum ion solutions. As a consequence, a. high degree of association overcomes the beneficial effect of increased concentration and gives a rational explanation of the failure of the higher concentrations of lithium ions in the case of the nitrite, chlorate and thiocyanate salts to show a lower vapor pressure than the less soluble, but more completely dissociated, lithium bromide. The intermediate vapor pressure of the lithium chloride also fits sultably into the pattern because the chloride 1on, beling smaller than the bromide lons, would be expected to assoctate to a greater extent than bromide fon but to a lesser extent than the other three which are known to be strong "complex formers."

In summary, therefore, we assign the effectiveness of a metallic salt absorbent for polar refrigerants in regard to vapor pressure lowering to three factors, namely: 
1. A high fonic potential of the cation favors a low vapor pressure.

2. A high solubility, particularly past the point where the mole ratio of refrigerant to absorbent becomes equal to the coordination number of the cation, favors a low vapor pressure.

3. Formation of bonds between the anion and cation in solution leads to increasing vapor pressure.

Unfortunately these three properties are interrelated in a generally unfavorable manner. For instance, as (1) becomes increasingly favorable, (2) and (3) tend to become less favorable. Similarly, as (2) Increases there is a general tendency for (3) to become less favorable. Thus, it would be anticipated that some one salt would exist in which the best balance of these three quantities would exist, and the prevalent bellef that trial and error procedures have disclosed this essentially optimum salt to be ifthium bromide are probably correct.

Antlclpating some of our later results and a few scattered reports by others, we find that $1 \mathrm{t}$ is not necessary for favorable values of all three factors to reside in the same substance. By combining salts which individually show a particularly favorable degree of one of these basic properties it is possible to achieve a mixture whose vapor pressure is substantially lower than can be achleved by attempting to maximize these three properties in the same substance.

In particular, a possible procedure would be to select a cation in which the best value of the lonic potential occurs (also considering such practical concepts as corrosion and toxicity), namely lithium, and improve the performance over the best present state of the art by mixing lithium salts In which high values of factors (2) and (3) are separately achleved.

Thus, this concept leads to the prediction that the combination of a relatively highly dissociated salt such as lithium bromide, lithium nitrate or lithium chloride can be used in conjunction with a salt showing lesser dissociation but higher molal solubility, such as lithium nitrite; 1ithium chlorate, or lithium thlocyanate to obtain a mixed salt solution with a lower 
vapor pressure than can be obtained with either salt separately, comparison being made between saturated solutions at room temperature. A variety of data has been taken in which virtually all pairs of the above mentioned salts have been examined and in each case the resultant vapor pressure-composition curve is in agreement with prediction.

The argument is not restricted to palrs of salts as it is possible to comblne, for example, two salts having high solubllity and low dissociation (i.e., Licl $\mathrm{O}_{3}$ and $\mathrm{LiNO}_{2}$ ) with a salt having lower solubility but higher dissociation (i.e., lithium bromlde) and obtain lower vapor pressures than can be obtained with any single salt of the set. A few such instances have been examined perfunctorily with the result anticipated.

of special interest would be combinations with lower vapor pressures than saturated lithium bromlde solutions. As lithium bromide is one of the more highly dissociated of the reasonably soluble lithium salts, the obvious direction to look for improvement is to add salts in which the solubility factor is very high (necessarily at the expense of the dissociation). In this connection we might look for considerable lmprovement from the extremely soluble 11thlum chlorate and lesser Improvements with lithlum nitrite or chloride. This is precisely what has been observed.

The above treatment is, at least experimentally, restricted to systems in which water is absorbed by lithium salts. This I regard as the situation of most practical significance although the concept presented probably can, and should, be extended. Specific areas of possible extension are:

1. No experiments have been made in which cations af various ionic potential are mixed. An extisting patent, however, teaches the use of caesium and rubidium salts (low Ionic potentlal, high solubility and high dissociation) in confunction with lithium salts (high Ionfc potential at expense of solublilty and dissociation) to produce low vapor pressures. 
2. It would seem that combinations of salts with lower vapor pressures than elther constituent salt could be realized for cations other than 11thium. Very few of these would be low enough to be of interest in absorption refrigeration.

3. It mfght be of interest to attempt to establish the previous pattern for refrigerants other than water. This could be a complex undertaking if the investigation were to achieve any width of scope.

\section{1-2 LITHIUM BROMIDE - WATER}

The system 11thium bromide-water has been extensively developed and any candidate system which would supersede this combination for solar absorption would necessarily show 1mproved vapor-pressure-solubility relationships. For reference purposes a copy of the Carrier Lithium Bromide Properties Chart, as edited for inclusion into the current ASHRAE Gulde and Data book by Mr. Lowell McNeely, has been included as Figure 1. 


\section{FIGURE ।}

EQUILIEFIUM CHAFT FOR AQUEOUS LITHIUM BROMIDE SOLUTIONS

\section{EQUATIONS}

1. $t=A t^{\circ}+B$

2. $t^{\prime}=(t-B) / A \quad(A)-(3.133362 E-3) x^{2}+(1.97658 E-5) x^{3}$

3. $A=-2.00758+.16976 x-(3.1333628-3) x^{2}+(1.97668$

5. $\log P=C+D /\left(t^{\prime}+459.72\right)+E /\left(t^{\prime}+459.72\right)^{2}$

6. $t^{\circ}=\frac{2 E}{\left(-D-\left(D^{2}-4 E(C-\log P)\right) \cdot 5\right)}-459.72$

TPRP. RANGE (REFRIGERANT) $0 \geq t^{\prime} \leq 2300^{\circ} \mathrm{F}$

TDP. RAPGE (SOLUTION) $40 \geq t \leq 350^{\circ} \mathrm{F}$

CONCENTRATION RUNGE

$490 \geqq x \leq 70 \%$

$C=6.21147$

$D=-2836.373$
$E=-337259.46$

$t^{\prime}=$ PEFRTGERANT TEMP ${ }^{\circ}$

$t=$ SJLUTION TOMP
$x=$ PERCENT LIBP

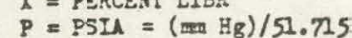

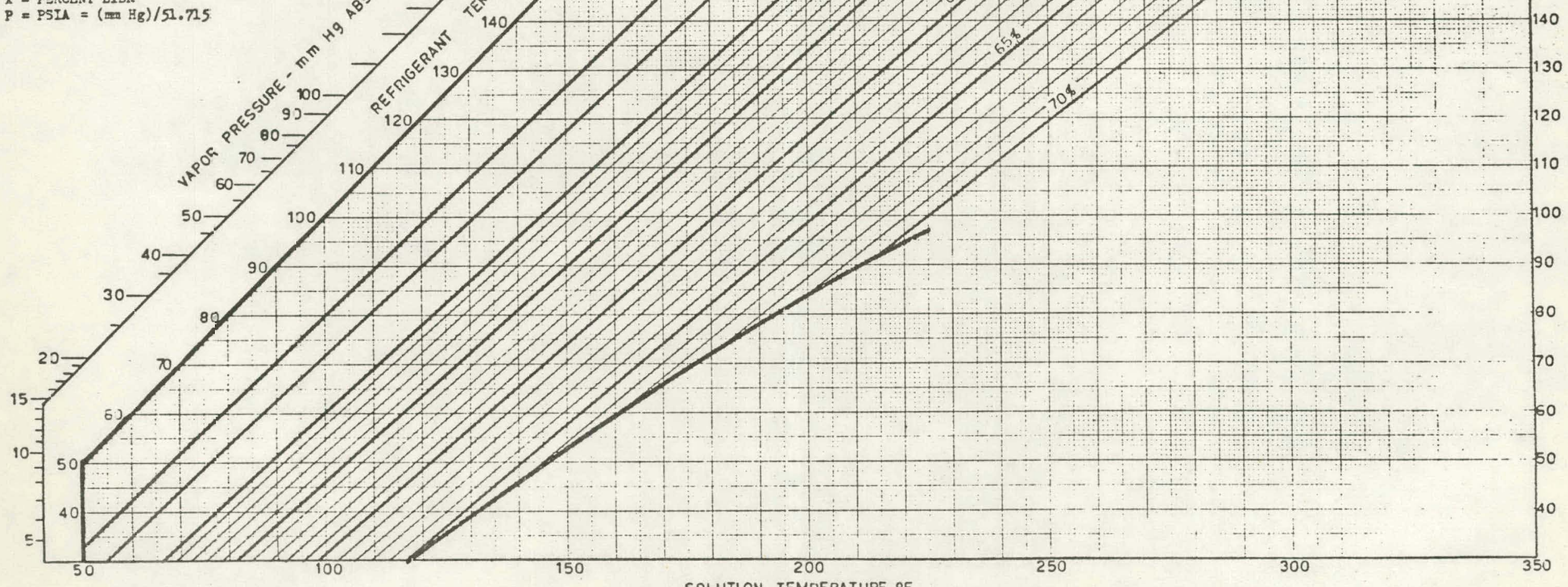




\section{2-0 EXPERIMENTAL RESULTS, SALTS AND WATER}

\section{2-1 SINGLE SALTS, SOLUTION VAPOR PRESSURES}

A variety of lithium salts were prepared on a small scale, either by acid-base reaction or by double decomposition reactions between lithium chloride and the sodium salt of the desired anion. These were allowed to stand in contact with saturated water solutions for a day or two at $20^{\circ} \mathrm{C}$ to insure that a reasonable approach had been made to equilibrium. The saturated solution was then placed in a glass container communicating with a closed end manometer degassed with a vacuum pump, and the vapor pressures measured over a range of temperature. In general, the salts selected were either known from the literature to be particularly soluble or from the size and other properties of the anion were expected to be very soluble.

In Figures 2 and 3 are presented a representative sample of these lithium salts, of which it will be noted that only lithium chlorate appears to have any vapor pressure gain over lithium bromide. Figure 4 contains more detalled information about the vapor pressure of lithium chlorate in the form of a series of Duhring plots. Table I contains numerical data on which these curves are based. This material will be discussed further in Section 2-2, Mixed Salt Results.

Another salt of particular interest is lithium iodide which has a high solubility and low vapor pressure at elevated temperatures. Figure 5 shows a family of Duhring plots for aqueous solutions of this material superimposed on a solubility curve. It will be noted that (as a result of a series of hydrates in the solid phase at various temperatures) there is a "hump" in the terminations of the Duhring lines at the solidus curve. It would present a challenging design problem to construct a machine which could use the attractive high temperature properties of lithium lodide solutions without frequent solidification problems in "crossing the hump." For a more optimistic report, see "Vapor Press of Aqueous Lithium Iodide Solutions," Bach, R. 0. and Boardmann, W. W., Jr. ASHRAE J. 33, November (1967). 


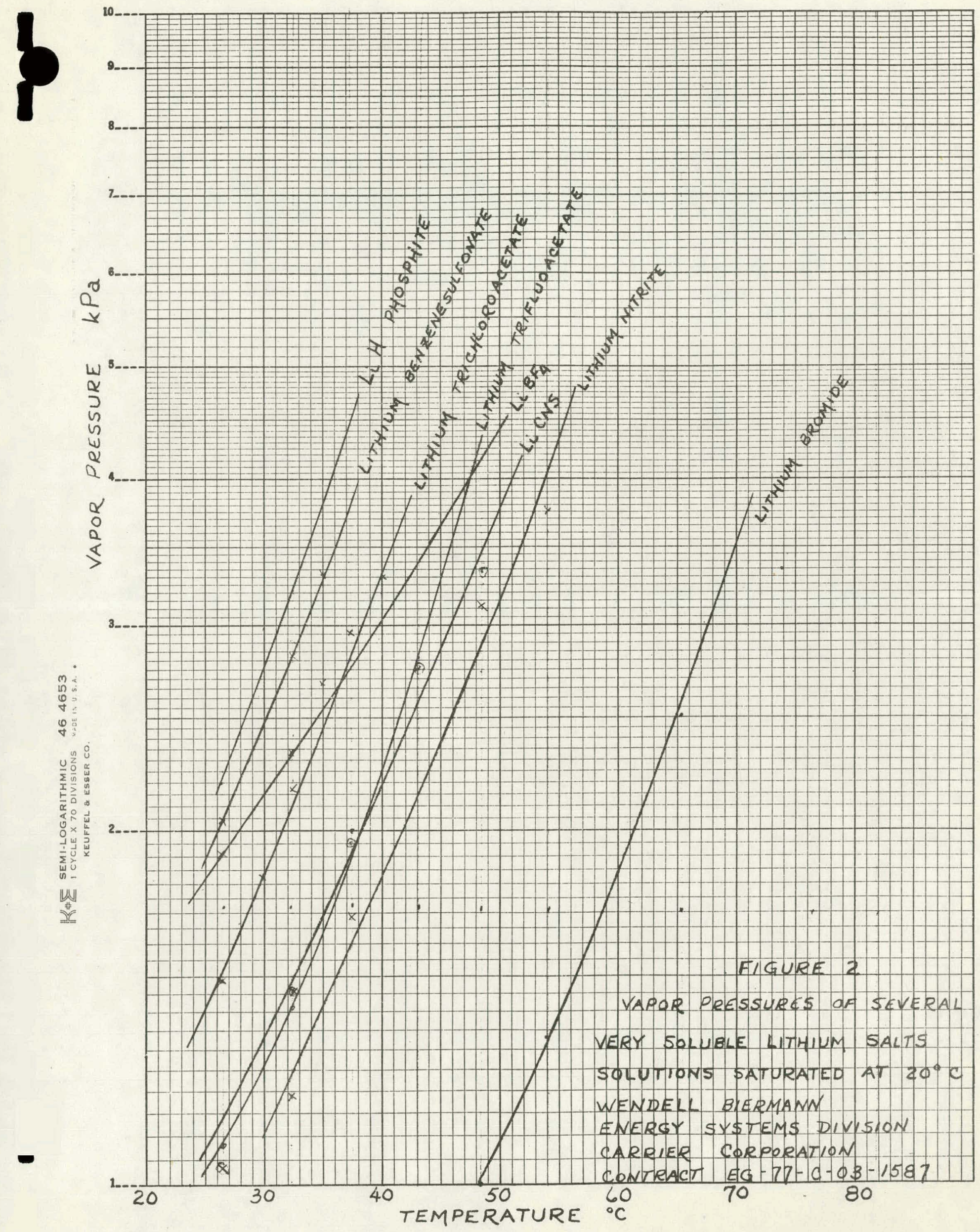




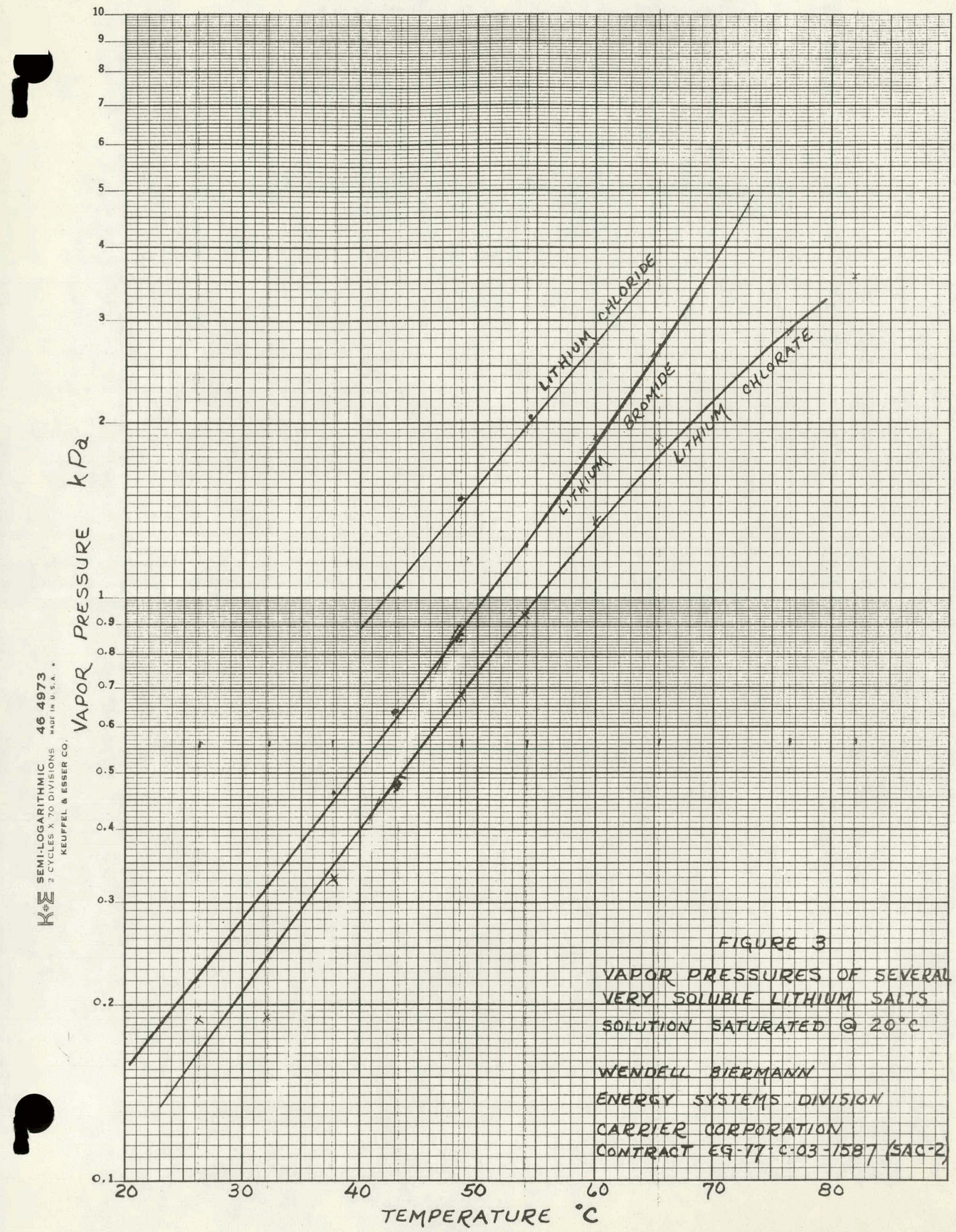



. 
120

FIG. 5

DÜHRING PLOT

LITHIUM IODIOE / WATER. SOLUTION

100 WENDELL BIERMANN

ENERGY SYSTEMS DIVISION

CARRIER CORPORATION

CONTRACT EG-77-C-03-1587 (SAC 2)

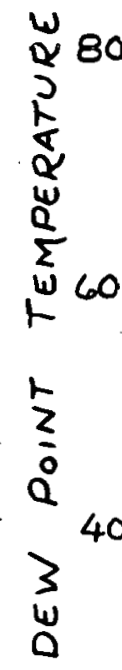

$+20$

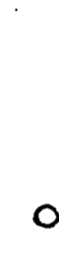

0

30

40

50

$\begin{array}{clcc}60 & 70 & 80^{\circ} & 90 \\ \text { SOLUTION } & \text { TEMPERATURE } & { }^{\circ} \mathrm{C} & \end{array}$

100

110

.120 


\section{TABLE I}

Lithlum Benzenesulfonate ${\mathrm{L} \emptyset \mathrm{SO}_{3}}_{3}$

Vapor pressure above saturated solution $\left(20^{\circ} \mathrm{C}\right)$

\begin{tabular}{|c|c|c|c|c|}
\hline $\mathrm{T}^{\circ} \mathrm{C}$ & $\mathrm{mm} \mathrm{Hg}$ & $\underline{\mathrm{kPa}}$. & $\underline{\mathrm{mm}} \mathrm{Hg}$ & $\mathrm{kPa}$ \\
\hline 26.67 & 15.8 & 2.11 & $15: 6$ & 2.08 \\
\hline 29.44 & 18.3 & 2.44 & $18: 2$ & 2.43 \\
\hline 32.22 & 21.5 & 2.87 & 21.2 & 2.83 \\
\hline 35.00 & 24.0 & 3.20 & 24.8 & 3.31 \\
\hline
\end{tabular}

Lithium Hydrogen Phosphite

$\begin{array}{lll}\frac{\mathrm{T}^{\circ} \mathrm{C}}{26.67} & \frac{\mathrm{mm} \mathrm{Hg}}{16.5} & \frac{\mathrm{kPa}}{2.20} \\ 29.44 & 20.2 & 2.69 \\ 32.22 & 24.1 & 3.21\end{array}$

Lithium Nitrite

$\begin{array}{lrl}\frac{\mathrm{T}^{\circ} \mathrm{C}}{26.67} & \frac{\mathrm{mm} \mathrm{Hg}}{6.3} & \frac{\mathrm{kPa}}{0.84} \\ 32.22 & 8.9 & 1.19 \\ 37.78 & 12.7 & 1.69 \\ 48.89 & 23.4 & 3.12 \\ 54.44 & 27.9 & 3.72\end{array}$

Lithium Hexfluorophosphate - Hydrolyzed on boiling

Lithium Tetrafluoroborate - Hydrolyzed rap1d1y

Ifthium Sulfidc - Hydrolyzed rapidly

$\operatorname{LiBF}_{4}$

$\begin{array}{lll}\frac{\mathrm{T}{ }^{\circ} \mathrm{C}}{26.67} & \frac{\mathrm{mm} \mathrm{Hg}}{14.4} & \frac{\mathrm{kPa}}{1.92} \\ 32.22 & 17.5 & 2.33\end{array}$


TABLE I (cont'd.)

Lithium Trifluoroacetate $\mathrm{LiCF}_{3} \mathrm{CO}_{2}$

$\frac{\mathrm{T}^{\circ} \mathrm{C}}{26.67}$
32.22
37.78
43.33

Lithium Trichloroacetate $\underline{\mathrm{p}} \mathrm{mm}$

8.1

10.6

15.0

21.2
P. $(\mathrm{kPa})$

1.08

1.41

2.00

2.83

$\frac{\mathrm{T}^{\circ} \mathrm{C}}{26.67}$
29.44
32.22
35.00
37.78
40.56

$\underline{\mathrm{P} m \mathrm{~m}}$

11.2

$\underline{\mathrm{P} \text { kPA }}$

1.49

13.7

1.83

16.2

2.16

20.0

2.67

22.2

2.96

25.0

3.33

Lithium Dichloroacetate

$\begin{array}{lrl}\frac{\mathrm{T}{ }^{\circ} \mathrm{C}}{23.89} & \frac{\mathrm{P} \mathrm{mm}}{7.5} & \frac{\mathrm{P} \mathrm{kPa}}{1.00} \\ 29.44 & 12.5 & 1.67\end{array}$

Lithium Thiocyanate

$\frac{T^{\circ} \mathrm{C}}{26.67}$
32.22
37.78
43.33
48.89

$\frac{P \mathrm{~mm}}{7.8}$

$\underline{\mathrm{P}} \mathrm{kPa}$

1.04

10.9

1.45

14.7

1.96

20.3

2.71

25.0

3.33 


\section{TABLE I (cont'd.)}

Lithium Thiosulfate

$\frac{\mathrm{T}^{\circ} \mathrm{C}}{26.67}$
32.22
37.78
43.33
48.89

$\underline{\mathrm{P}} \mathrm{mm}$

8.7

$\underline{\mathrm{PPa}}$

1.16

11.2

1.49

15.3

2.04

20.6

2.75

24.7

3.29

Lithium Iodide Data D.P. $\left({ }^{\circ} \mathrm{C}\right)=\mathrm{m} \mathrm{T}_{\text {sol }}+\mathrm{b}$

$\begin{array}{lcc} & \stackrel{\mathrm{m}}{\mathrm{m}} & \underline{\mathrm{b}} \\ 50 \% & 0.93500 & -12.683 \\ 60 \% & 0.95152 & 23.572 \\ 65 \% & 0.90370 & -33.893 \\ 70 \% & 0.77777 & -37.531 \\ 75 \% & 0.70513 & -42.621 \\ 80 \% & 0.68831 & -52.251 \\ 85 \% & 0.70000 & -67.000\end{array}$

Crystallization Curve

\begin{tabular}{cr} 
Solution Axis ${ }^{\circ} \mathrm{C}$ & $\frac{\text { D.P. Axis }{ }^{\circ} \mathrm{C}}{10.67}$ \\
\hline 10.00 & -6.00 \\
31.11 & 4.44 \\
32.22 & 6.11 \\
43.33 & 7.78 \\
54.44 & 11.11 \\
65.56 & 16.94 \\
71.11 & 17.78 \\
78.06 & 9.44 \\
82.22 & -0.28 \\
93.33 & 3.33 \\
104.44 & 8.89 \\
118.33 & 14.44
\end{tabular}


VAPOR PRESSURES OF LITHIUM CHLORATE SOLUTIONS

TABLE I (cont'd.)

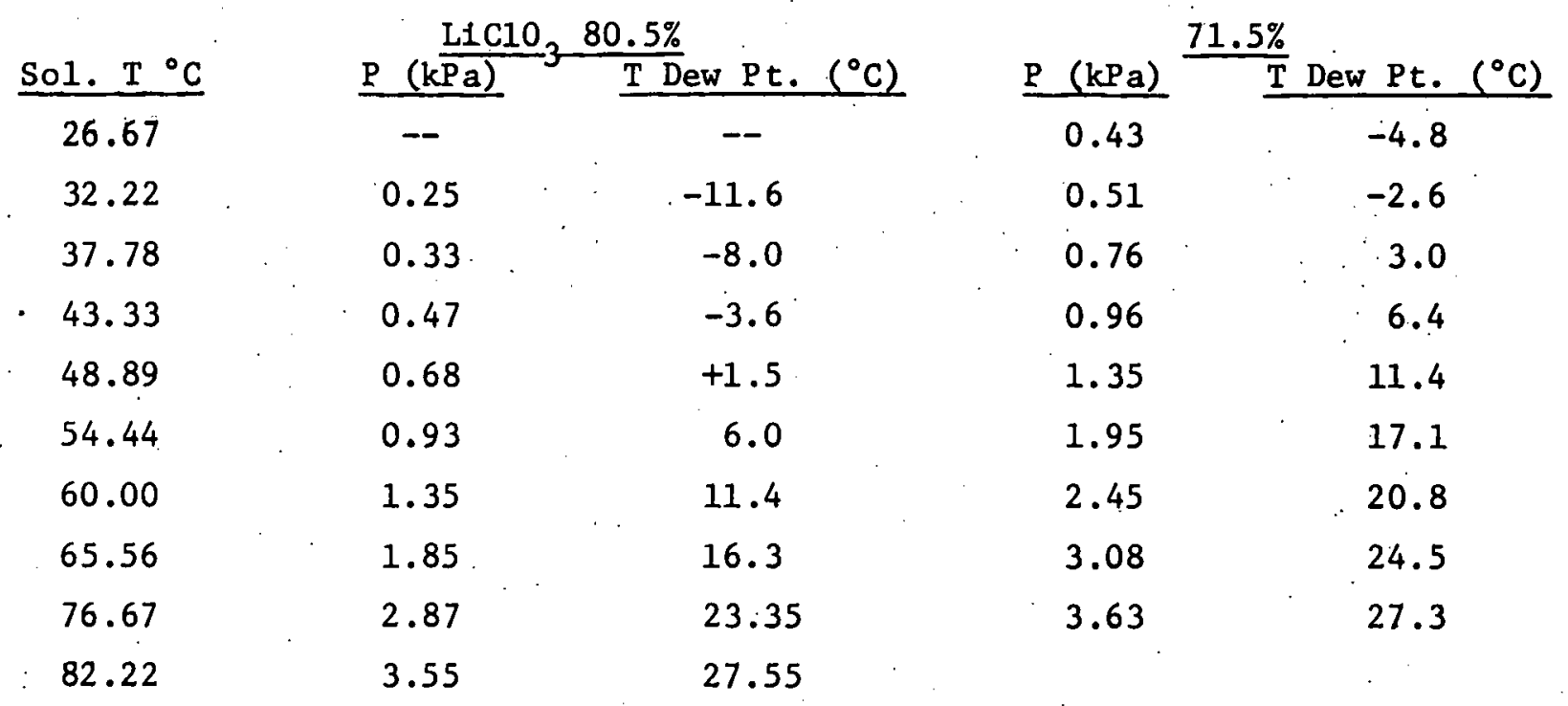

$80.5 \% \mathrm{LIClO}_{3}$

$$
\mathrm{T}_{\text {ref }}=0.78622 \mathrm{~T}_{\text {sol }}-37.03
$$

$71.5 \% \mathrm{LiClO}_{3}$

$$
\mathrm{T}_{\text {ref }}=0.71027 \mathrm{~T}_{\text {sol }}-23.71
$$




\section{TABLE I (cont'd.)}

Vapor pressures of $\mathrm{LiClO}_{3}$ Solutions (cont'd.)

\begin{tabular}{|c|c|c|c|c|c|}
\hline 63 & & & & & \\
\hline So1. I ${ }^{\circ} \mathrm{C}$ & Dew Pt. & So1. T & Dew Pt. & Sol. T & Dew Pt. \\
\hline 38.9 & 15.6 & 71.1 & $20: 2$ & 61.1 & 23.1 \\
\hline 41.1 & 17.4 & 68.9 & 18.5 & 58.9 & 21.1 \\
\hline 43.3 & 19.3 & 65.6 & 15.9 & 56.7 & 19.3 \\
\hline 45.6 & 21.2 & 62.2 & 13.3 & 54.4 & 17.5 \\
\hline 47.8 & 23.0 & 58.9 & $10.7^{\circ}$ & 52.2 & 15.6 \\
\hline 50.0 & 24.9 & 55.6 & 8.1 & 48.9 & 12.6 \\
\hline 51.3 & 26.0 & 52.2 & 5.7 & 46.7 & 10.8 \\
\hline & & 48.9 & 3.2 & 44.4 & 8.9 \\
\hline & & 47.8 & 2.4 & 43.7 & 8.2 \\
\hline & & 56.7 & 9.3 & & \\
\hline & & 61.1 & 12.8 & & . \\
\hline . & & 65.5 & 16.3 & & . \\
\hline
\end{tabular}

$$
\begin{aligned}
63.2 \% \quad \mathrm{~T}_{\mathrm{H}_{2} \mathrm{O}} & =0.83851 \mathrm{~T}_{\text {sol }}-17.035 \\
73.4 \% \quad \mathrm{~T}_{\mathrm{H}_{2} \mathrm{O}} & =0.85216 \mathrm{~T}_{\text {sol }}-28.984 \\
81.3 \% \quad \mathrm{~T}_{\mathrm{H}_{2} \mathrm{O}} & =0.76919 \mathrm{~T}_{\text {sol }}-34.432 \\
\mathrm{~T}_{\text {ref }} & =[0.97327-0.0024601(\mathrm{x})] \mathrm{T}_{\text {sol }}+50.96-1.0706(\mathrm{x}) \\
\text { where } & \mathrm{T} \text { 1s temperature, }{ }^{\circ} \mathrm{C} \text {. } \\
& \mathrm{x} \text { 1s solute concentration, weight percent. }
\end{aligned}
$$




\section{2-1.1 other Salts and Salt-like Materials}

There are few cations whose effective ionic potential is as high as lithium. Those which might be examined are beryllium salts which would be eliminated on the basis of toxicity and cost. In the second row of the periodic table, we find sodium and magnesium, neither of whose salts show the solvating ability of lithium. The last remalning cation in the upper left of the periodic table is hydrogen, and the affinity of the hydrogen ion, in the form of strong acids, for water is well known. No data on these strong acids are included on the basis that their corrosive properties render them improbable candidates for absorption refrigeration.

Some of the lighter transitional metals, notably zinc and to a lesser extent cadmfum show high effective ionic radii because of their polarizability. We will look at these in our section on mixed salts.

One last possible single salt-like class would be the very soluble alkali metal (except 1ithium) hydroxides in which the anion shows very strong coordinating power to water. Following below are some Duhring plots and a solubility diagram for sodium-hydroxide water. Its thermodynamic promise is marginal and the generally corrosive properties of strong caustic soda lead to a decision to reject. Conslderable property data are avallable:

"Caustic Soda" Solvay Technical and Engineering Service, Bulletin No. 6, Allied Chemical Company, New York.

Bertetti, J. W. and McCabe, W. L., "Sodium Hydroxide Solutions: Heat of Dilution," Ind. Eng. Chem. 28, 247 (1936)

Ibid "Specific Heats" 28, 375 (1936).

Hayward, A. M. and Perman, E. P., "Vapor Pressure and Heat of Dilution - Part VII Vapor Pressures of Aqueous Solutions of Sodium Hydroxide and of Alcoholic Sn1,utinns of Salsium Chlorate," Trans. Faraday Soo. 37, 60 (1931).

Figure 6 presents some Duhring curves for sodium hydroxide solutions in water and Figure 7 gives crystallization temperatures for the various solid phases of sodium hydroxide. 
$30-1$ FIGURE DÜHRNVG CURVES FOR THE SYSTEM SODIUM TYDROXIDE- MATER

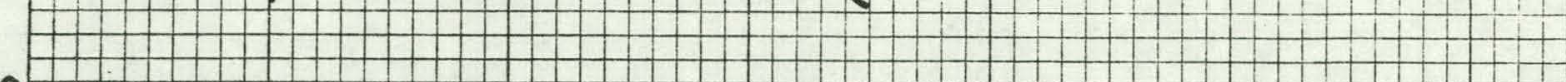

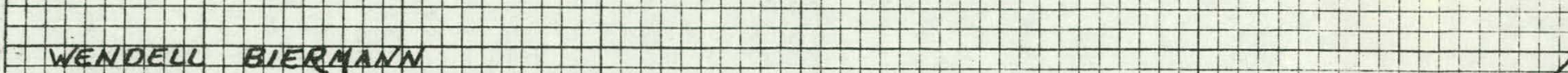
eneedr SUSTEMS DNVISION CARTER CORDopATIN

CONTEACt EG-77-C-03-158] (SAC-2)

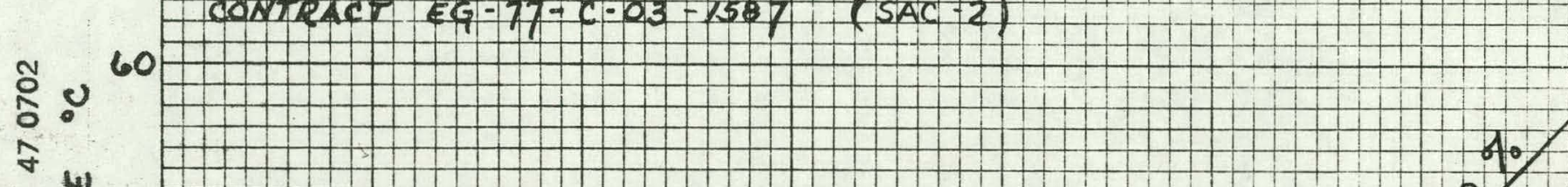

$\sum_{5}^{2} 50$

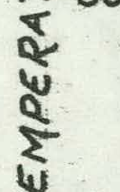

3

$\frac{1}{2}$

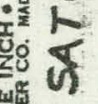

鮆

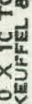

幽

10

0

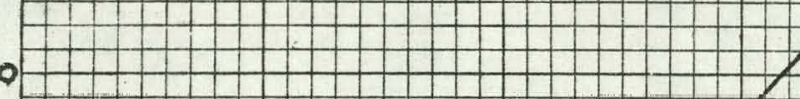

20:

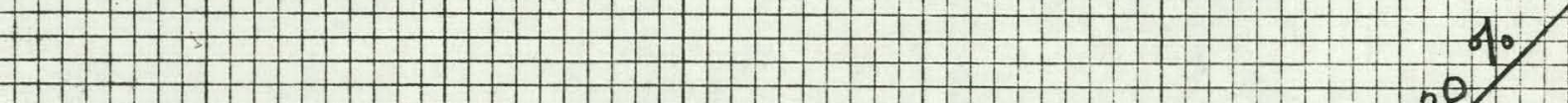

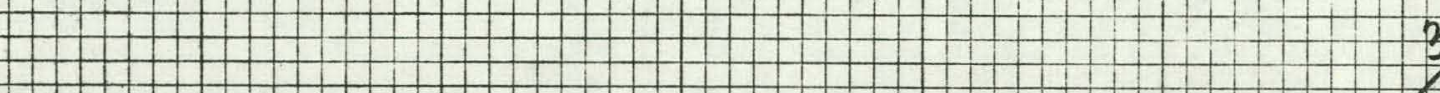

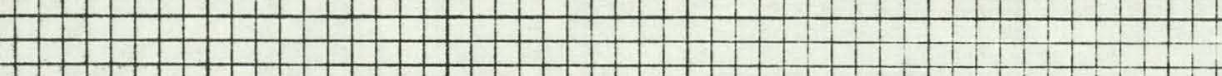

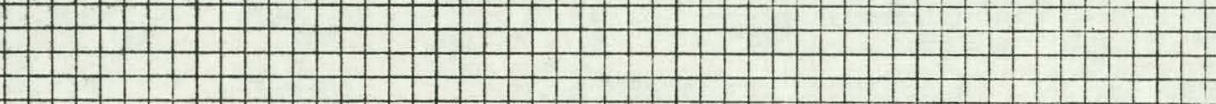

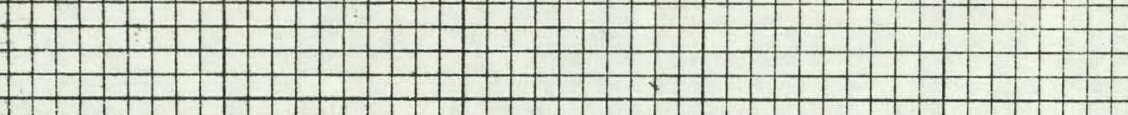

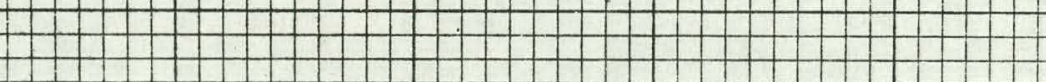

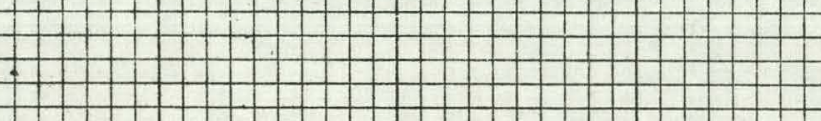

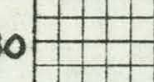

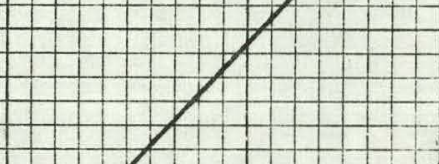

$1+-$

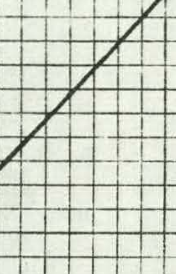

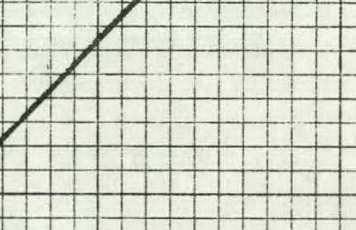
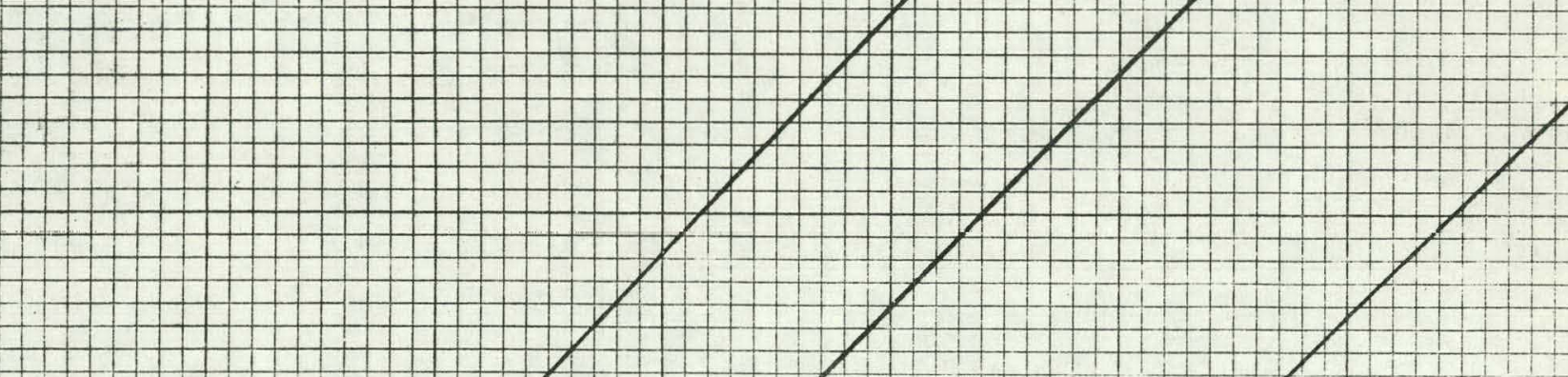

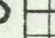

+

$+1$ $+1+1$

(

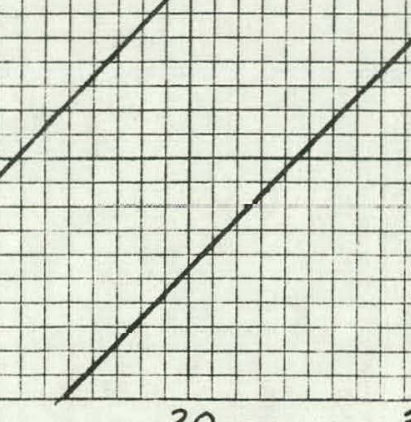

$-10$

10

20

30

40

50

SOLUTION

70

80

$\cdot \mathrm{C}^{90}$

100

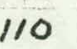

120

140 
$-21-$

FIGURE 7

SOLUBILITY OF SODIUM HYDROXIDE IN WATER

WENDELL BIERMANN

ENERGY SYSTEMS DIVISION

CARRIER CORPORATION

CONTRACT EG-77-C-03-1587 (SAC 2)

$100-$

$80-$

$060-$

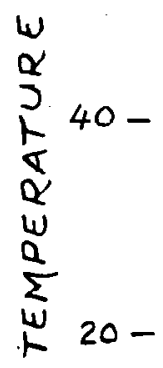

o-

$-10-$

$-20-$

20

30

40

50

60

70

80

90

$\%$ NASH BY WEIGHT 


\section{2-2 MIXTURES OF SALTS}

A considerable body of mixed salts with water have been suggested for tise as absorption refrigeration systems. Unfortunately, most of these have been qualified only with respect to vapor pressure and such problems as heat transfer coefficients and chemical stabilities have not been addressed adequately. There does not seem to be any systematic way of covering such systems and our presentation wil1 be pretty much at random, covering some of the more interesting or well known systems in detall and leaving the others as items in which the reader may find utility which this author overlooked.

\section{2-2.1 Lithium Chlorate/L1thium Bromide-Water}

This chemical combination was explored in considerable detail by the Research Division of Carrier Corporation as a promising candidate for a gas fired-air cooled absorption cooling cycle. Two patents ${ }^{(1)}$ cover the use of Ifthium chlorate alone or in mixture, as an absorbent.

Figure 8 shows the variation of Dew Point as a function of the mole fraction $\mathrm{LiBr}$ in the $\mathrm{LiBr} / \mathrm{LiClO}{ }_{3}$ solute, comparing solutions at $60^{\circ} \mathrm{C}$ and having a common crystallization point of $25^{\circ} \mathrm{C}$. These data indicate that the optimum composition is around $\mathrm{N}_{\mathrm{LiBr}}=0.43$ and subsequent discussion assumes this concentration ratio of salts.

Figure 9 shows the vapor pressure variation of $\mathrm{LiClO}_{3} / \mathrm{L} \mathrm{BBr}$ solutions In the form of a family of Duhring plots. Figures 10 and 11 present differential heats of dilution and specific heat capacities. Numerical data (vapor pressures only in part) leading to these flgures are collected as Table II. Table II also includes some absorber film heat transfer coefficients which, with appropriate heat transfer additives turn out to be not much worse than lithium bromide, and also some experimentally measured corrosion rates on possible materials of construction.

(1) U.S. Patents 3,316,728 and 3,316,736. W. J. Blermann. "Absorption Refrigeration Systems" Granted 5/2/67. Assigned to Carrier Corporation. 
12

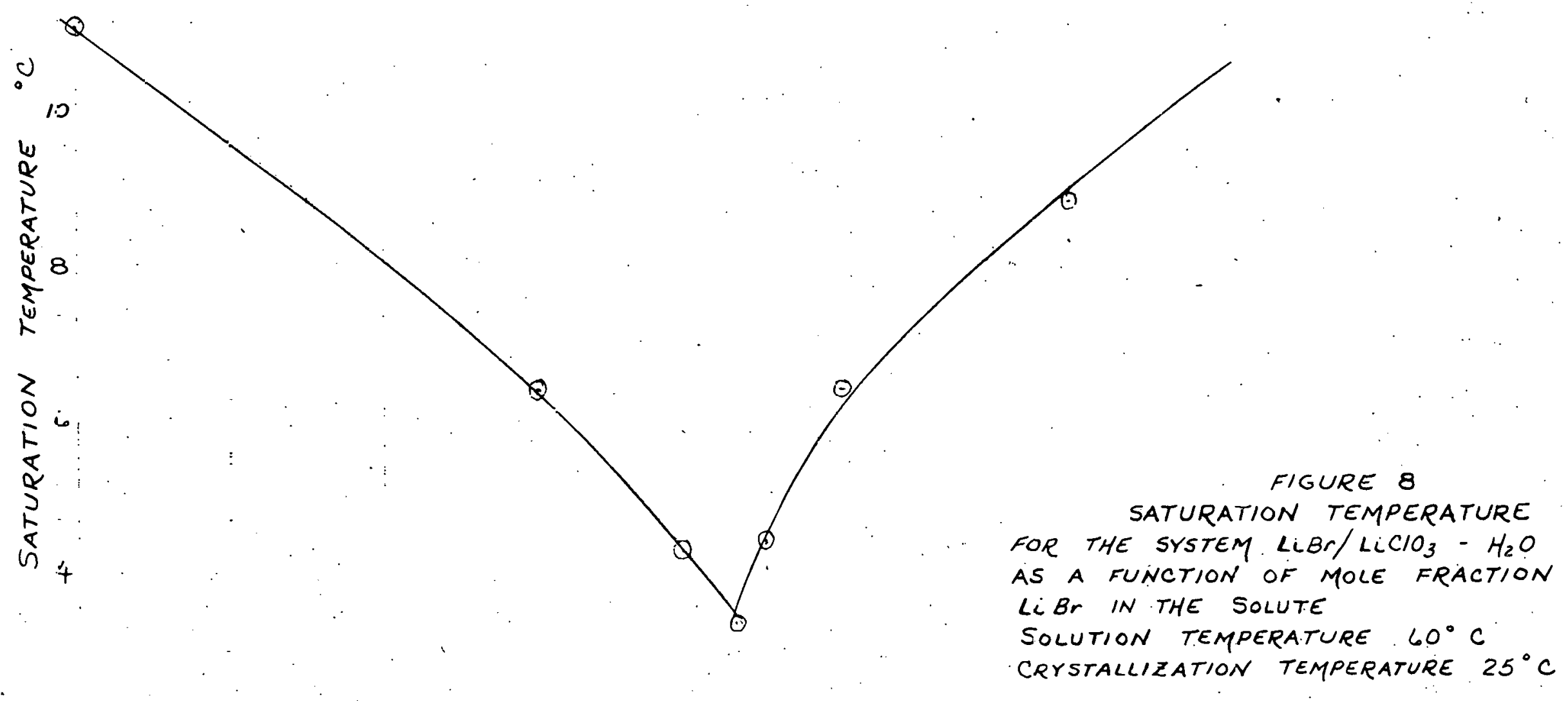

2

$\begin{array}{lll}0 & 1 & .2\end{array}$

$\begin{array}{lllll}.3 & 4 & .5 & .6\end{array}$

$\cdot 7$

.8

.9

1.0 
LiBr/ $\mathrm{LiClO} 3-\mathrm{H}_{2} \mathrm{O}:\left(\mathrm{N}_{\text {LiBr }}=0.44 \pm 0.01\right)$

BASED ON CARRIER RESEARCH DIVISION DATA

+

WENDELL BIERMANN
ENERGY SYSTEMS DIVISION

50

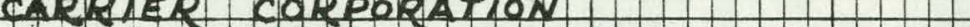

contract E9-77-c-03-1587) (54c-2)

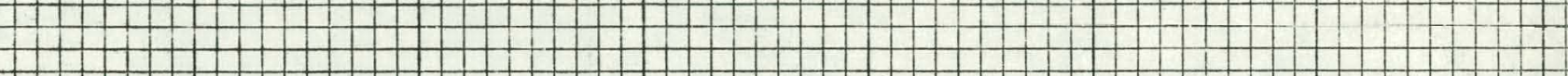

\section{ถั}

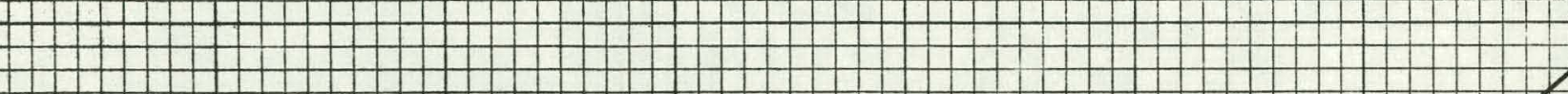

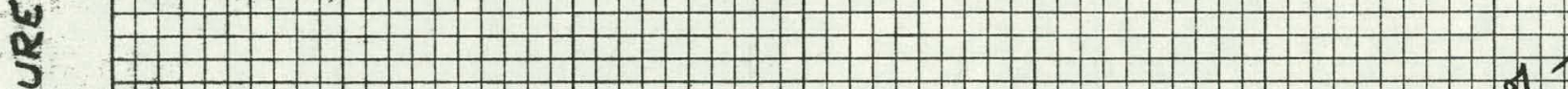

₹ 30

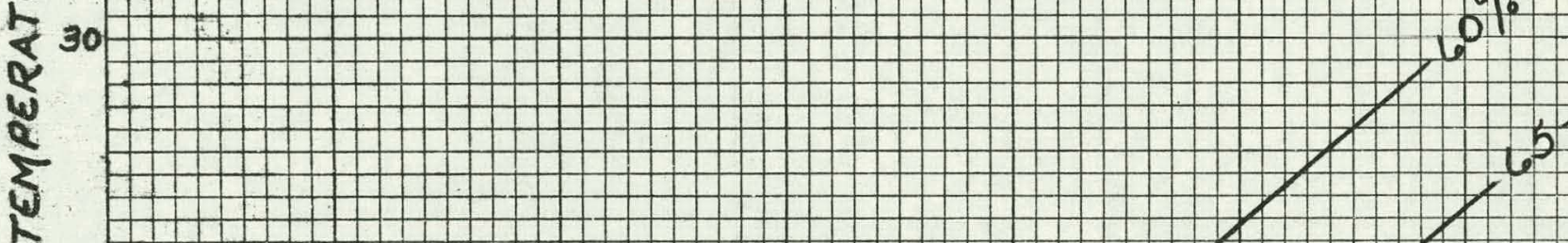

$\frac{1}{2}$

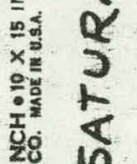

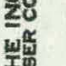

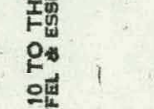

sis

$-10$

\begin{tabular}{l|l|l|l|l}
10 & 1
\end{tabular}

8

$-20$

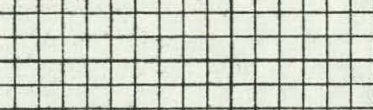

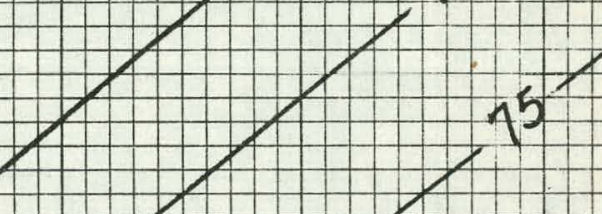

15

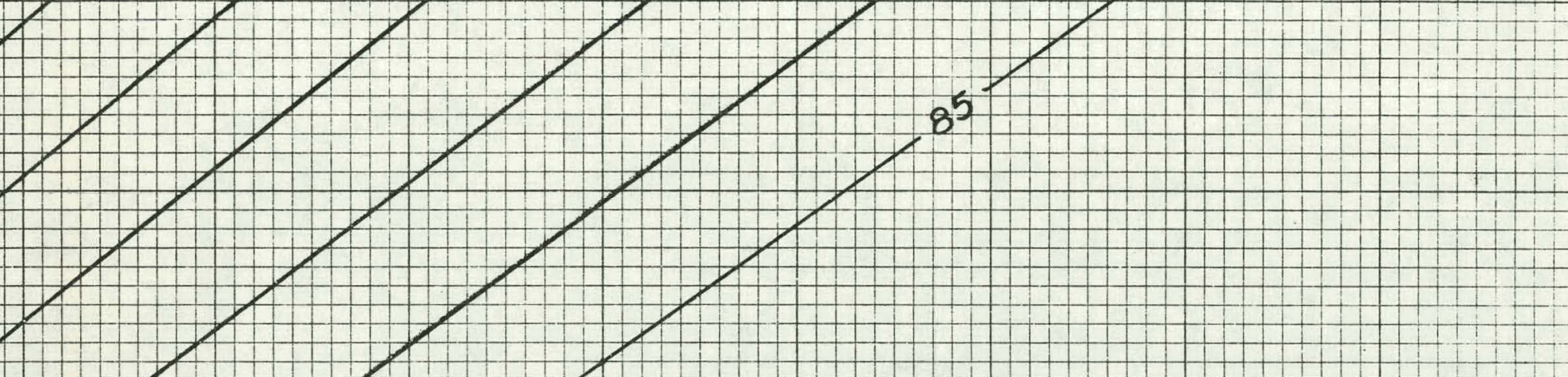

-

\begin{tabular}{|l|l|}
\hline & \\
\hline & \\
\hline & \\
\hline & \\
\hline & \\
\hline & \\
\hline & \\
\hline & \\
\hline
\end{tabular}

$-30$

+11

10

20

10

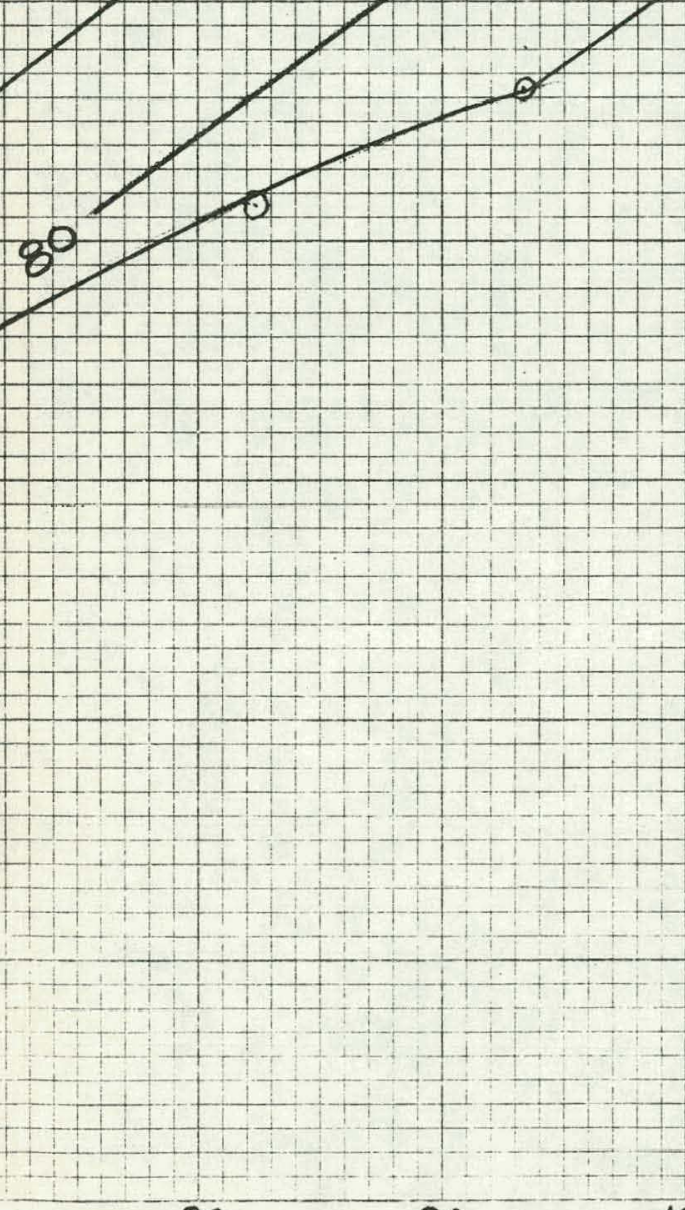

80

90

100

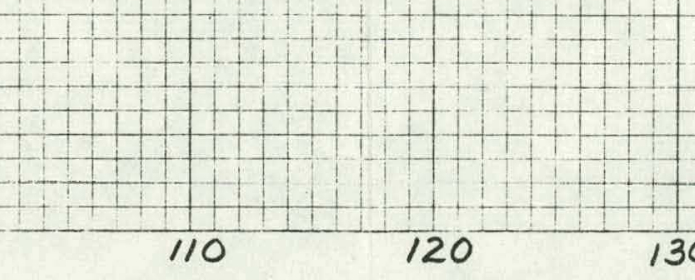

130 
FIGURE 10

DIFFERENTIAL HEAT OF DILUTION OF $\mathrm{LC} \mathrm{ClO}_{3} / \mathrm{LIBr}$ - $\mathrm{H}_{2} \mathrm{O}$ SOLUTIONS

BASED ON DÜHRING DATA

WENDELL BIERMANN

ENERGY SYSTEMS DIVISION'

CARRIER CORPORATION

CONTRACT EG-77-C.03-1587

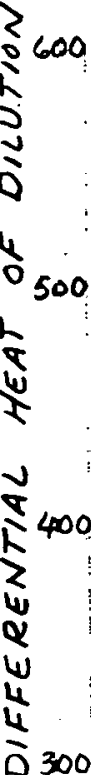

200

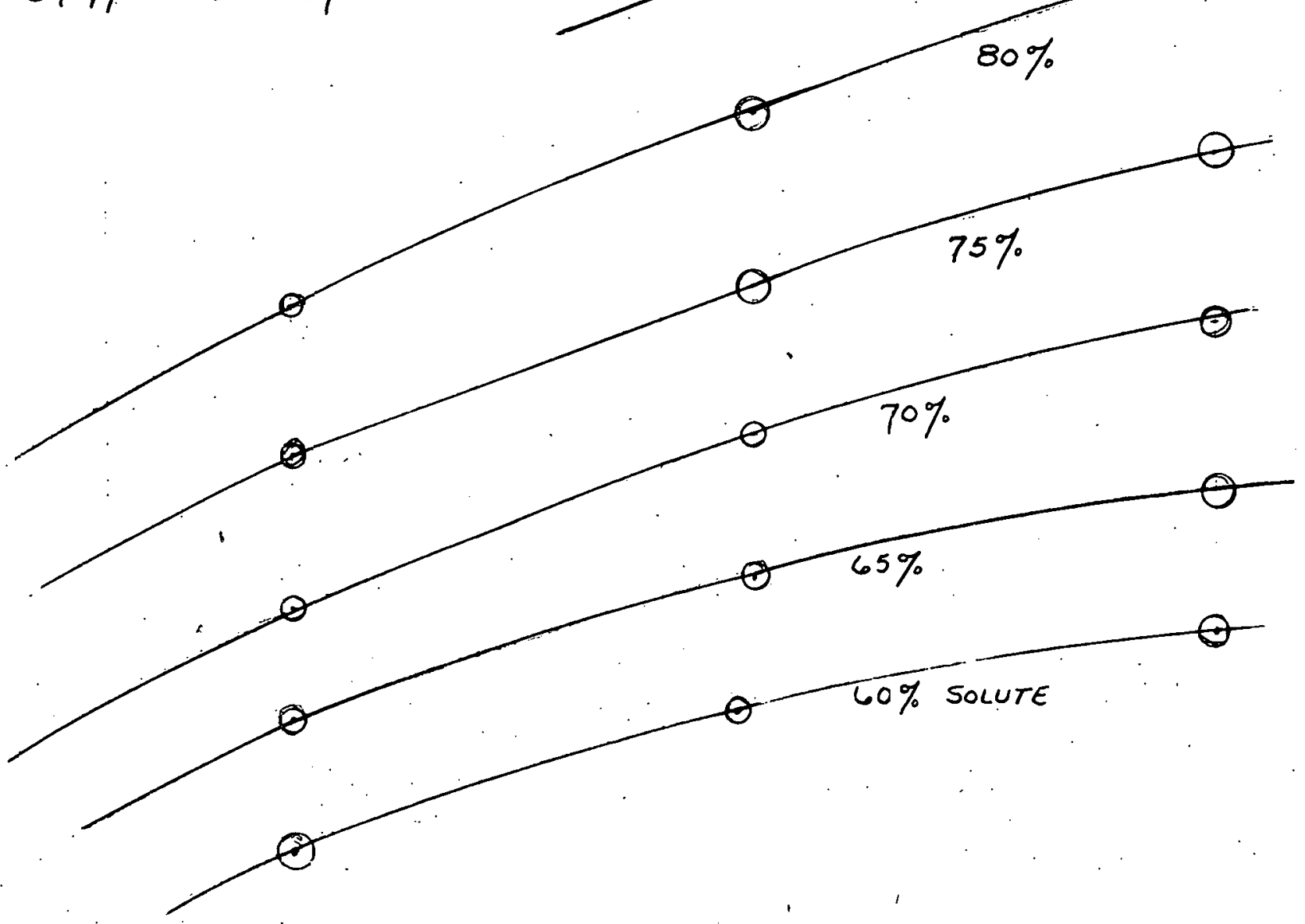

190

20

40

60

80

100

120

140

160

180 
2.1

$65 \%$

20

$x_{x}^{\infty}$

1.9

ta

$75 \%$

No

$\frac{u}{u}$

1.7

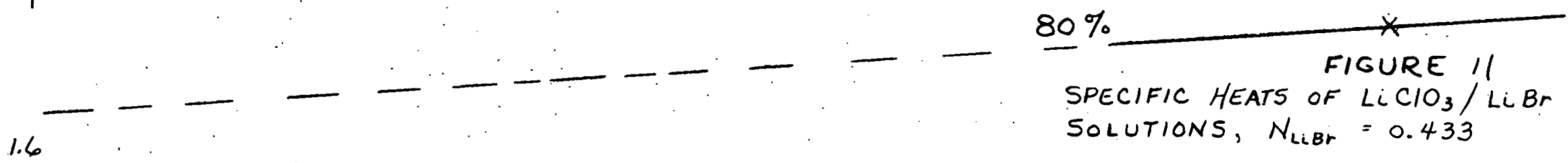

WENDELL BIERMANN.

ENERGY SYSTEMS DIVISION CARRIER CORPORATION

$\begin{array}{lll}1.5 & 10 & 20\end{array}$

30

CONTRACT EG- $77 \cdot-0-03-1587$ (SAC 2)

$\begin{array}{cc}40 & 50 \\ \text { TEMPERATURE } & { }^{\circ} \mathrm{C}\end{array}$

70

80

90

100 


\section{TABLE II}

\section{Properties of $\mathrm{LIClO}_{3} / \mathrm{LIBr} / \mathrm{H}_{2} \mathrm{O}$}

Vapor Pressure Curve for a solution temperature of $60^{\circ} \mathrm{C}$ and crystallization temp. of $25^{\circ} \mathrm{C}$ as function of mole fraction LiBr in the solute.

$\begin{array}{lr}N_{L I B r} & \text { Dew Poin } \\ 0.0 & 11.1 \\ 0.300 & 6.33 \\ 0.395 & 4.22 \\ 0.430 & 3.33 \\ 0.450 & 4.39 \\ 0.500 & 6.33 \\ 0.650 & 8.78 \\ 1.00 & 15.22\end{array}$

Spectfic Heats of $\mathrm{LiClO} / \mathrm{LiBr} / \mathrm{H}_{2} \mathrm{O}$-solutions.

Mole Fraction $\mathrm{L} 1 \mathrm{Br}=0.433$ Reliability $\pm 5 \%$.

Concentration Temperature Specific Heat

We1ght Percent

Temperature Spectflc Heat

65.5

26.1

$\mathrm{kJ} / \mathrm{kg}$

Prects1on

70.0

28.9

83.9

2.13

$\pm 0.02$

1.98

2.07

$\pm 0.02$

25.0

1.83

83.9

1.88

\pm .04
\pm 0.03

80.0

83.9

1.68

$+0.01$ 


\title{
TABLE II(Cont1nued)
}

\author{
Dew Point Measurement ${ }^{N_{L i B r}}=0.45$
}

\begin{tabular}{|c|c|c|c|c|c|}
\hline $\begin{array}{c}\text { Wt\% solute } \\
79.7\end{array}$ & · & Wt\% & $\begin{array}{l}\text { solute } \\
5.72\end{array}$ & 77. & \\
\hline Solution $\mathrm{T}\left({ }^{\circ} \mathrm{C}\right)$ & Dew $\operatorname{Pt}\left({ }^{\circ} \mathrm{C}\right)$ & So1 $\mathrm{T}^{\circ} \mathrm{C}$ & $\mathrm{T}_{\mathrm{D} . \mathrm{P} .}{ }^{\circ} \mathrm{C}$ & Sol $\mathrm{T}\left({ }^{\circ} \mathrm{C}\right)$ & $\mathrm{T}_{\mathrm{D}: \mathrm{P} .}\left({ }^{\circ} \mathrm{C}\right)$ \\
\hline 82.2 & 18.6 & 75.6 & 19.33 & 82.2 & 22.00 \\
\hline 81.1 & 17.7 & 74.4 & 18.53 & 81.1 & 21.22 \\
\hline 80.0 & 16.9 & 73.3 & 17.72 & 80.0 & 20.42 \\
\hline 78.9 & 16.1 & 72.2 & 16.61 & 78.9 & 19.47 \\
\hline 77.8 & 15.2 & 71.1 & 15.78 & 77.8 & 18.69 \\
\hline 76.7 & 14.4 & 70.0 & 15.00 & 76.7 & 17.69 \\
\hline 75.6 & 13.7 & 68.9 & 14.14 & 75.6 & 16.85 \\
\hline 74.4 & 12.7 & 67.8 & 12.88 & 74.4 & 15.86 \\
\hline 73.3 & 11.9 & 66.7 & 12.44 & & \\
\hline 72.2 & 11.2 & 65.6 & 11.64 & 72.2 & 14.28 \\
\hline 71.1 & 10.3 & 64.4 & 10.78 & 71.1 & 13.50 \\
\hline 70.0 & 9.6 & 63.3 & 9.89 & 70.0 & 12.58 \\
\hline 68.9 & 8.7 & 62.2 & 9.06 & 68.9 & 11.81 \\
\hline 67.8 & 7.8 & 61.1 & 8.19 & 67.8 & 10.94 \\
\hline 66.7 & 7.0 & 60.0 & 7.33 & 66.7 & 10.06 \\
\hline 65.6 & 6.1 & 58.9 & 6.50 & 65.6 & 9.28 \\
\hline 64.4 & 5.4 & 57.8 & 5.61 & 64.4 & 8.42 \\
\hline 63.3 & 4.5 & & & 63.3 & 7.56 \\
\hline 79.50 wt\% & & & & 62.2 & 6.71 \\
\hline 82.2 & 17.50 & & & 61.1 & 5.86 \\
\hline 81.1 & 16.61 & & . & 60.0 & 4.96 \\
\hline 80.0 & 15.89 & & & & \\
\hline 78.9 & 15.19 & & $.70 \%$ & & \\
\hline 77.8 & 14.06 & $\mathrm{~T}_{\mathrm{D} . \mathrm{I}}$ & $=0.74255$ & $\mathrm{~T}_{\text {sol }}-42.50$ & \\
\hline 76.7 & 13.28 & & $72 \%$ & & 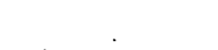 \\
\hline 75.6 & 12.58 & $\mathrm{~T}_{\mathrm{D} .1}$ & $=0.76927$ & $T_{\text {sol. }}-38.85$ & \\
\hline 74.4 & 11.83 & 7 & $.00 \%$ & & \\
\hline 73.3 & 11.06 & $\mathrm{~T}_{\mathrm{D}_{.1}}$ & $=0.76609$ & $\mathrm{~T}_{\text {sol }}-40.98$ & \\
\hline 72.2 & 10.17 & & & & . \\
\hline 71.1 & 9.42 & & $.50 \%$ & & \\
\hline 70.0 & 8.61 & $\mathrm{~T}_{\mathrm{D}, 1}$ & $=0.72141$ & Isol- 41.89 & . \\
\hline 68.9 & 7.69 & & & & . \\
\hline 67.8 & 6.94 & & & & $\therefore$ \\
\hline 66.7 & 6.06 & & & & \\
\hline 65.6 & 6.22 & & & & 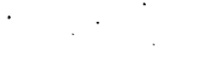 \\
\hline 64.4 & 4.39 & & & & \\
\hline 63.7 & 3.89 & & & & \\
\hline
\end{tabular}


TABLE II (Contined)

Dew Point Measurement $\mathrm{N}_{\mathrm{LIBr}}=0.43$

\begin{tabular}{|c|c|c|c|c|c|}
\hline \multicolumn{2}{|c|}{76.16 st\% Solute } & \multicolumn{2}{|c|}{77.60 ut\% } & \multicolumn{2}{|c|}{$80.7 \%$} \\
\hline $\mathrm{T}(\mathrm{sol}){ }^{\circ} \mathrm{C}$ & Dew $\operatorname{Pt}\left({ }^{\circ} \mathrm{C}\right)$ & $\mathrm{T}(\mathrm{s} 01)^{\circ}$ & $\mathrm{T}_{\mathrm{D} . \mathrm{P} .}{ }^{\circ}$ & Tsol & D.P. ${ }^{\circ}$ \\
\hline 73.3 & 15.4 & 75.6 & 15.3 & 87.8 & 18.97 \\
\hline 72.2 & 14.7 & 74.4 & 14.3 & 86.7 & 18.22 \\
\hline 71.1 & 13.9 & 73.3 & 13.4 & 85.6 & 17.46 \\
\hline 70.0 & 13.1 & 72.2 & 12.6 & 84.4 & 16.56 \\
\hline 68.9 & 12.3 & 71.1 & 11.9 & 83.3 & 15.67 \\
\hline 67.8 & 11.3 & 70.0 & 11.0 & 82.2 & 14.89 \\
\hline 66.7 & 10.4 & 68.9 & 10.3 & 81.1 & 14.19 \\
\hline 65.6 & 9.6 & 67.8 & 9.3 & 80.0 & 13.25 \\
\hline 64.4 & 8.8 & 66.7 & 8.5 & 78.9 & 12.58 \\
\hline 63.3 & 8.0 & 65.6 & 7.6 & 77.8 & 11.61 \\
\hline 62.2 & 7.1 & 64.4 & 6.8 & 76.7 & 10.89 \\
\hline 61.1 & 6.2 & 63.3 & 5.9 & 75.6 & 10.16 \\
\hline 60.0 & 5.4 & 62.2 & 5.1 & 74.4 & 9.39 \\
\hline 58.9 & 4.4 & 60.0 & 3.3 & $\cdot 73.3$ & 8.58 \\
\hline 57.8 & 3.6 & & & 73.1 & 8.44 \\
\hline
\end{tabular}

$78.94 \%$ Solute

77.77

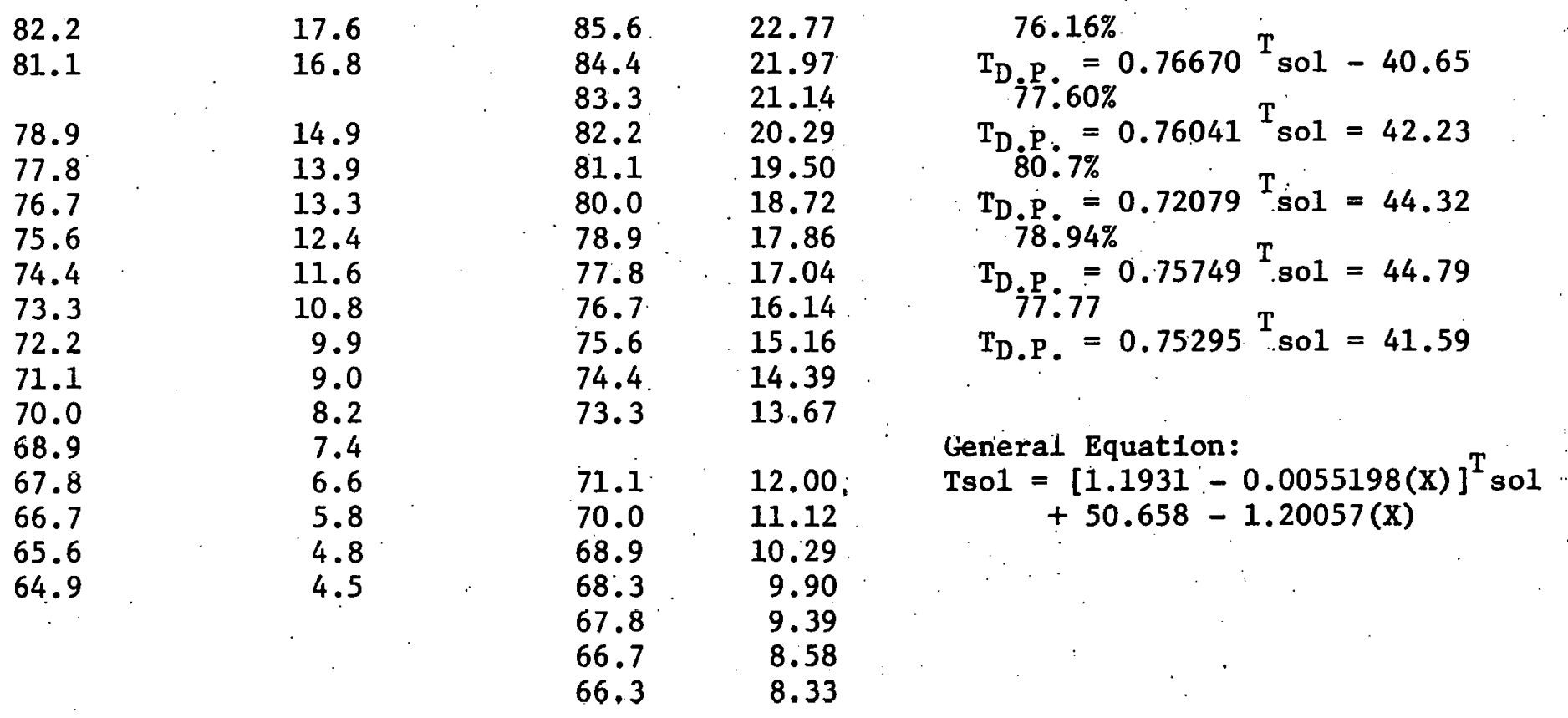


TABLE II (Continued)

Differential Heats of Dilution $\mathrm{LiClO}_{3} / \mathrm{LIBr}-\mathrm{Hz} \quad \mathrm{N}_{\mathrm{LIBr}}=0.433$

Wt\% Solute

60

65

70

7.5

80

85
Heat of Dilution $\mathrm{kJ} / \mathrm{kg}$, water

\begin{tabular}{llr}
$60^{\circ} \mathrm{C}$ & $104^{\circ} \mathrm{C}$ & $160^{\circ} \mathrm{C}$ \\
\hline 164.8 & 239.1 & \\
232.1 & 308.7 & 278.5 \\
292.4 & 385.3 & 352.8 \\
373.7 & 464.2 & 443.3 \\
454.9 & 557.0 & 533.8 \\
& 636.0 & 636.0 \\
& & 728.8
\end{tabular}

Corrosion Studies $350^{\circ} \mathrm{F}$, atr free

90/10 Cupronickel $\quad 486 \mathrm{mdd}$

Inconal

5.5 mdd

Titanium

0.2 mdd

Zircalloy

Copper

$0.0 \mathrm{mdd}$

Carbon Stee1

$1340: 0$

$0.3-0.5 \mathrm{mdd} *$

*See text for explanation.

Heat Transfer Coefficients, Film side

Vertical Tube Absorber

$\begin{array}{lclc}\text { Absorbent } & \text { Concentration } & \text { Additive } & \text { No }\left(\mathrm{W}_{\mathrm{m}}-2{ }^{\circ} \mathrm{C}\right) \\ \mathrm{LiBr} & 58 \% & \text { octyl alcohol } & 1817 \\ \mathrm{LiBr} / \mathrm{LiClO} \mathrm{O}_{3} & 76 \% & \text { none } & 369 \\ \mathrm{LiBr} / \mathrm{LIClO} 3 & 75 \% & \text { amine } & 1334\end{array}$

Horizontal Tube Absorber

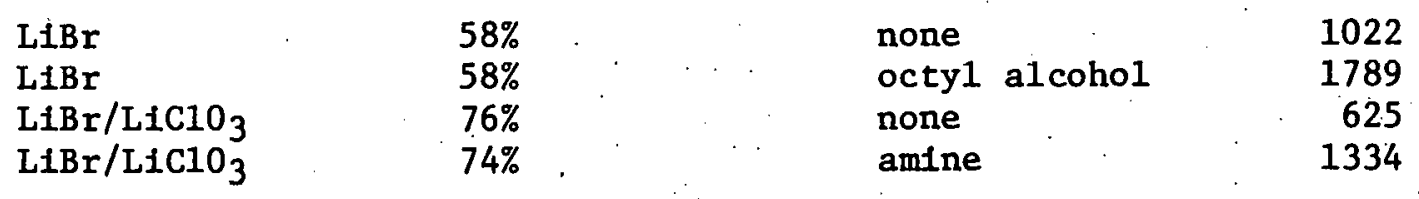

Experimental Bolling Point

Wt\% Solute $(\mathrm{N}=0.43 \mathrm{LIBr})$

$$
\begin{aligned}
& 76.1 .6 \\
& 77.6 \\
& 78.94 \\
& 80.7
\end{aligned}
$$

Normal Bolling Point

${ }^{\circ} \mathrm{C}\left( \pm 1^{\circ} \mathrm{C}\right)$

$18 \overline{5} .6$

189.6

193.5

198.4 
Figure 12 gives an approximate cycle calculation at the assigned conditions of $95^{\circ} \mathrm{F}$ ambient air and $230^{\circ} \mathrm{F}$ collector leaving temperature. A COP of $66 \%$ is predicted with individual component loadings being not significantly different than we are accustomed to seeing with water cooled lithium bromide. An improved heat exchanger or allowing the collector leaving temperature to rise by another $10^{\circ} \mathrm{C}$ (giving a concentration spread of $69.4 \%$ to $77.5 \%$ ) would further improve the performance.

This system was never developed because the highly aggressive nature of lithium chlorate, a powerful oxidizing agent even when somewhat Inhibited by $0.1 \%$ lithium hydroxide, could not be reliably controlled in the presence of the chlorate. Occasionally an inclusion in the iron would allow a couple to be set up, resulting in catastrophic local corrosion. In practice there seemed to be no reasonable way of avoiding this sort of thing, so with copper and fron both eliminated as constructional materials, first cost projections became unacceptably high for the market then existing.

A second problem was that of a supply of 1ithium chlorate: Presently the experimental amounts sold are made by reacting lithium sulfate with barium chlorate, filtering off the resultant barium sulfate and concentrating the lithium chlorate by evaporation. This is not economically practical if a product line were to be supported. We had a reasonable measure of success in an electrolytic process, using a proprietary electrode, preparing lithium chlorate on a semi-pilot scale.

For solar use, the system $\mathrm{L}_{1 \mathrm{C} 10} \mathrm{~L}_{3} \mathrm{LBr}-\mathrm{H}_{2} \mathrm{O}$ may look more promising since first cost can be absorbed by reduced collector area if one has a high COP system. On balance of all factors the antifreeze additive system presently under development remains the most promising a priori. Should there be some unexpected obstacle, $\mathrm{LiClO}_{3} / \mathrm{LIBr}$ may be a good back-up system. 


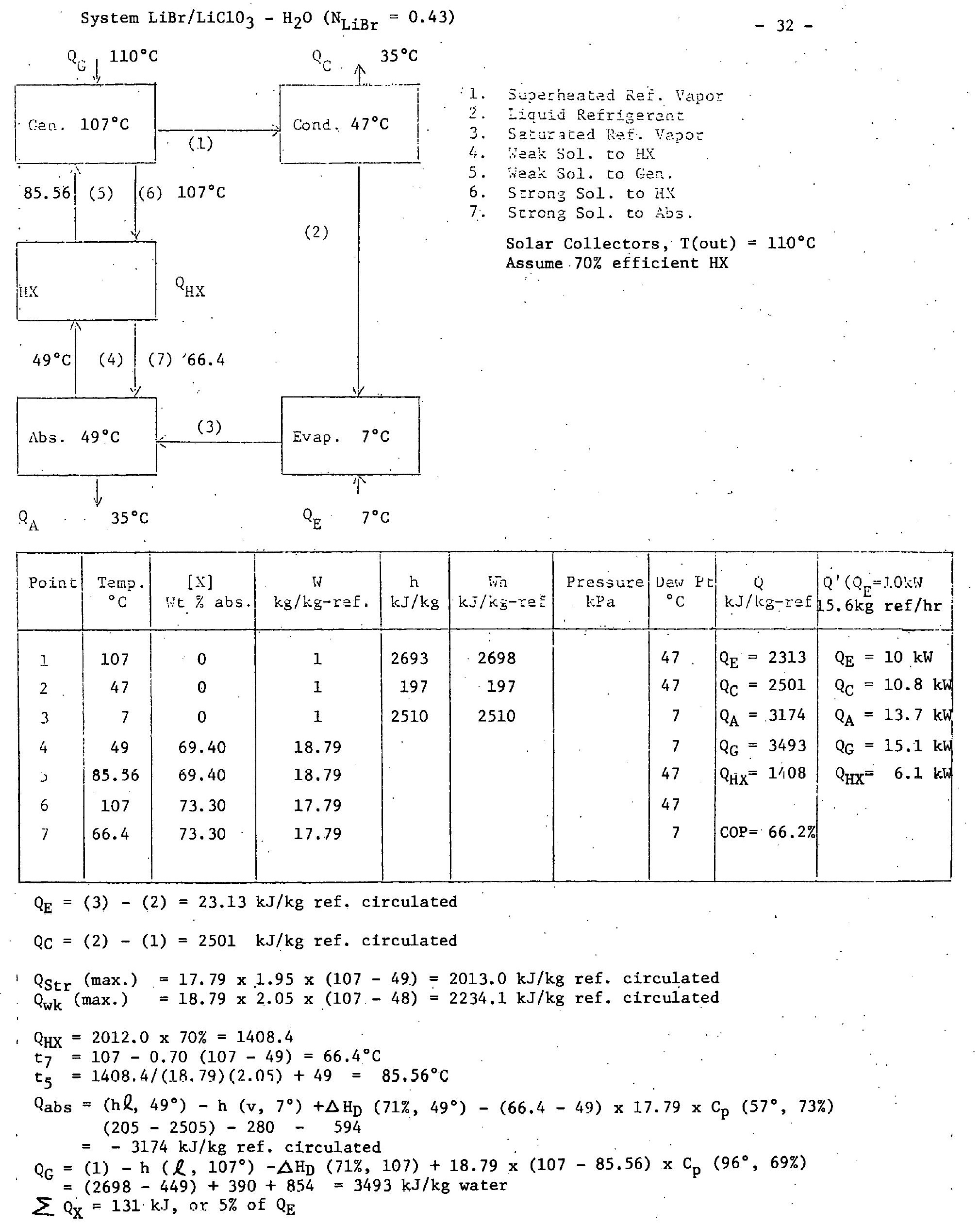




\section{2-2.2 Lithium Acetate-Lithium Chloride}

This system was studied as a good example of a mixture of one strongly dissoclated salt (the chloride) with a less completely dissociated salt. As shown on Figure 13, over a range of mole fraction lithium acetate ( $\mathrm{N}_{\text {LiOAc }}$ ) from 0 to about 0.2 mixtures of 11thium chloride and lithium acetate, saturated at $20^{\circ} \mathrm{C}$, show lower vapor pressures than does lithlum chloride when saturated under the same conditions. Table III, below, summarizes the $60^{\circ} \mathrm{C}$ information.

\section{TABLE III}

EFFECT ON VAPOR PRESSURE LOWERING, ADDITION OF LIOAC to LiC1

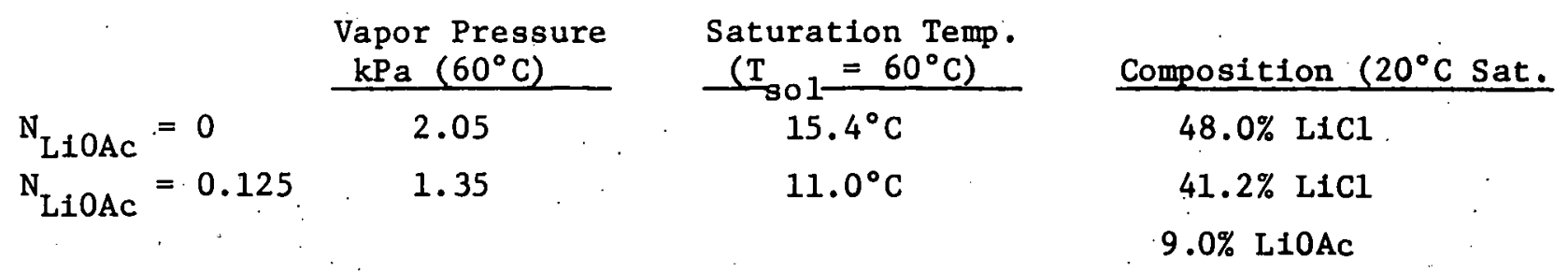

The magnitude of saturation temperature gain did not justify any additional work.

\section{2-2:3 Other Lith1um Salt Mixtures}

Figure 14 shows vapor pressures at $60^{\circ}$ for mixtures of lithium nitrite/1ithium chlorate, lithium thiocyanate/1ithium bromide ${ }^{(1)}$ and lithium thiocyanate/lithium chloride. It will be noticed that the less dissociated 1ithium thiocyanate shows a pronounced minimum in the region of 0.5 mole fraction with the strongly dissociated lithium bromide, but with the less dissociated chloride the minimum is not as well defined. With two salts of the less dissociated type, the nitrite and chlorate, no minimum is seen. These data are consistent with the hypothesis guiding our search; but the solutions were not considered to be candidates for development.

(1) R. A. Macriss, "Physical Properties of Modified L1Br Solutions;" Symposium on Absorption Alr Conditioning Systems, American Gas Association, Chicago 1968, for further discussions of lithium bromidc/lithium thiocyanate and other systems. 

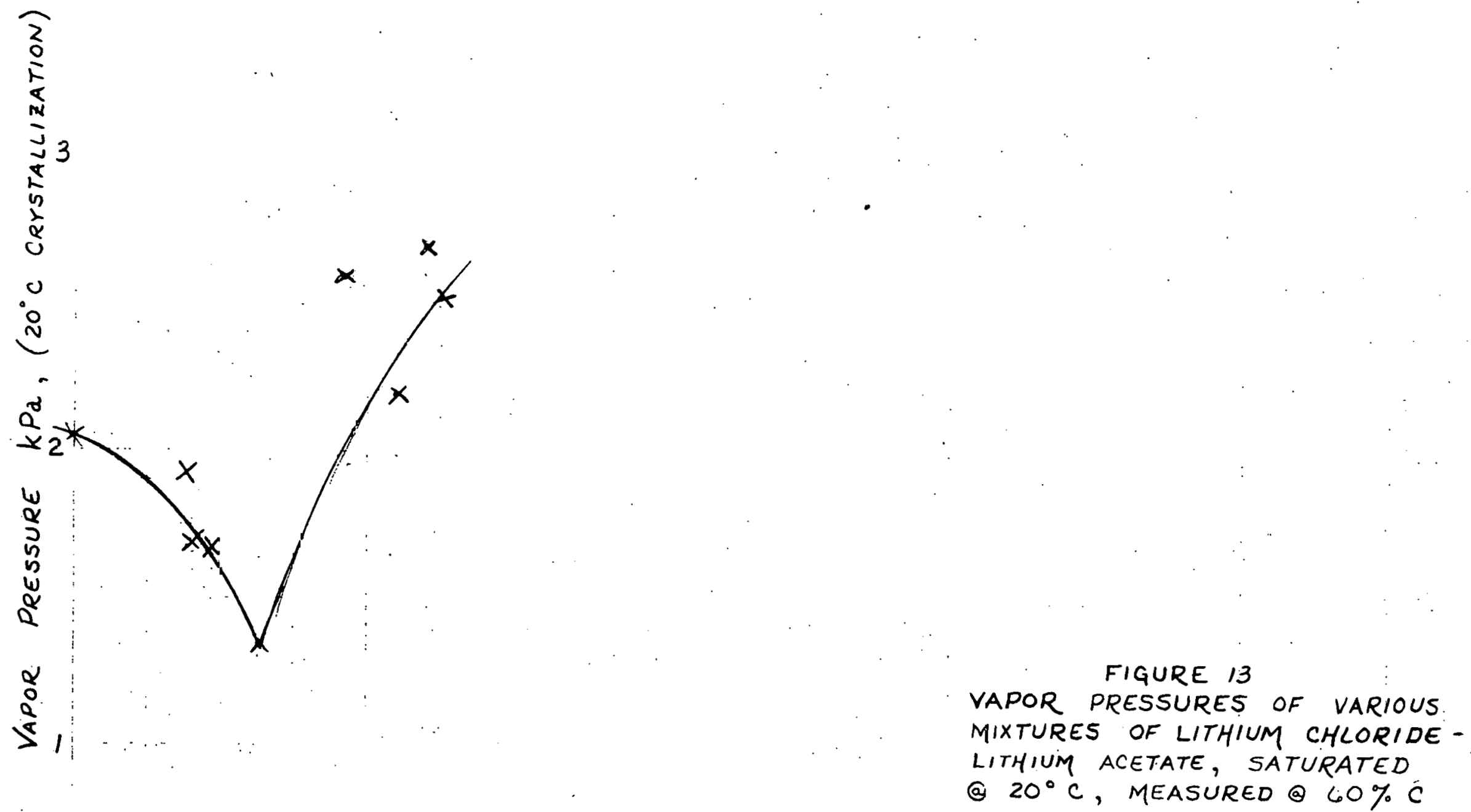
3

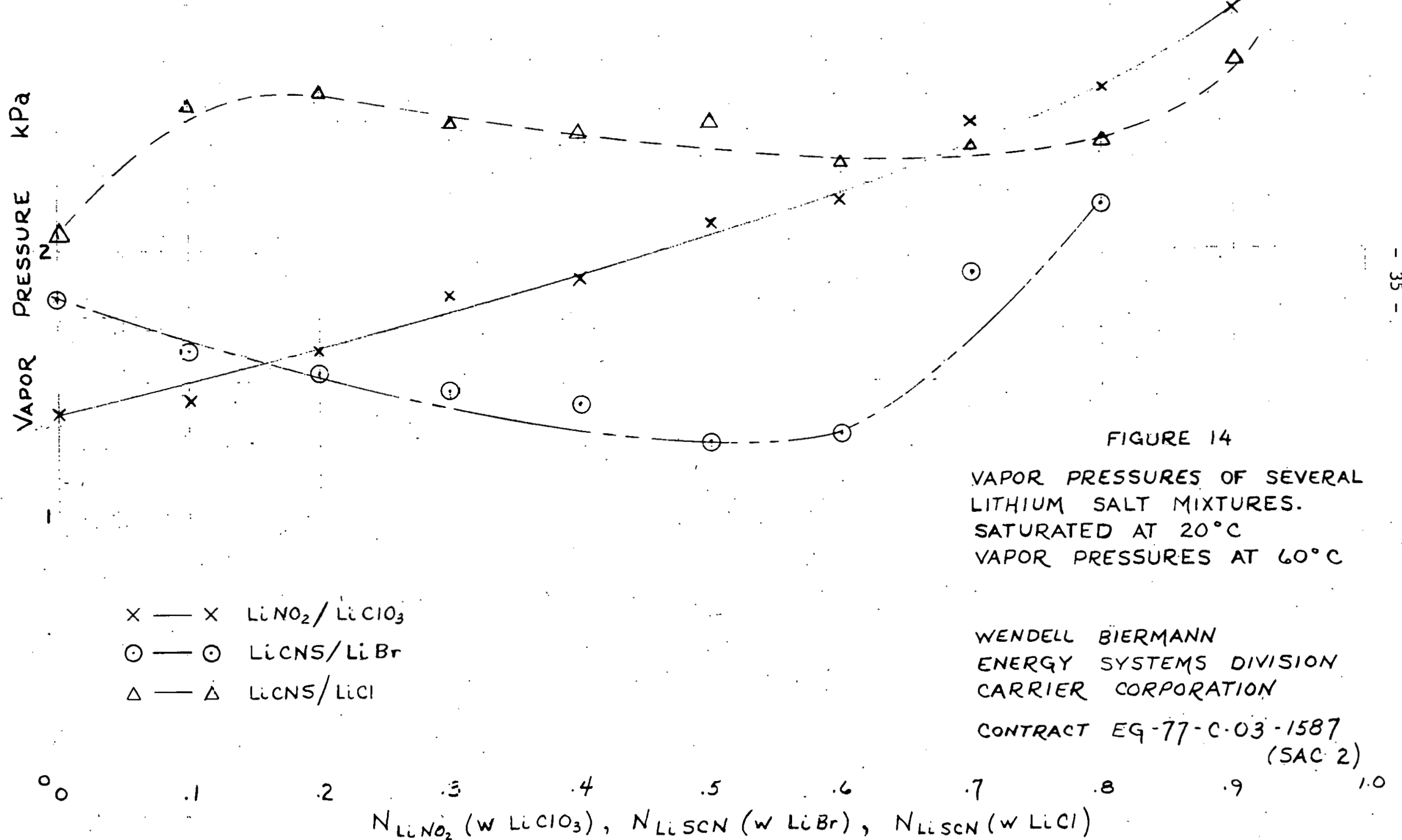


Mixtures of lithlum chloride and lithium bromide show a pronounced reduction in vapor pressure over elther salt, compared at identical crystallization and test temperatures. (1) The magnitude of the gain is only a few degrees In dewpolnt, not large enough to be of significant help.

The system 1ithium bromide/1ithium Lodide-water has also appeared in the literature several times. (2),(3) our own evaluation of this system has disclosed no advantages over 11thium bromide, when crystailization temperatures near usual ambient are considered.

(1) U.S. Patent 2,091,983. S. B. Heath and L. R. Minger. Granted $9 / 7 / 37$. "Dehumidifying Solution," Assigned to Dow Chemical.

(2) "The Absorption Cooling Process," Institute of Gas Technology Research Bullet1n \# 14, page 3 (Chicago 1957)

(3) U.S. Patent 3,524,815. Hensel, W. E, Jr. and Harlowe W. H. Jr., "Lithium Bromide-Lithium Iodide Compositions for Absorption Refrigeration System," Assigned to Arkla Industries, Inc., August 18, $1970 .$. 


\section{2-3 LITHIUM SALTS, WITH NON-LITHIUM SALTS}

The number of combinations of lithlum salts with non-lithium salts is potentially very large, but the number in which significant amount of interaction can be expected, or has been observed, is small. Generally, the second salts which have aroused any interest have been either highly dissociated halide salts (from cations toward the lower left of the Pertodic Table) or are transitional metal halides, usually from Groups $1 \mathrm{~b}$ or $2 \mathrm{~b}$.

Examples of the use of highly dissociated halide salts are the use of caesium bromide with lithium bromide ${ }^{(1)}$ and calcium bromide and/or calcium chlorlde $(2),(3),(4),(5)$ with lithium halides. The vapor pressure gains are not impresstve and no information is available in print about heat transfer properties, corrosion rates, etc., which in the practical case are equally Important.

(1) U.S. Patent 3,004,919. W. L. Rush \& W. G. Watters, "Absorbent Composition for any Absorbent Refrigeration System," Granted 10/17/61, Assigned to Borg-Warner.

(2) U.S. Patent 2,143,007. S. B. Heath and L. R. Minger, "Dehumidifying Solution," Granted 1/10/39. Ass Igned to Dow Chem1cal

(3) U.S. Patent 2,143,008. S. B. Heath, "Composition for Dehumidifying Gases," Granted 1/10/39, Assigned to Dow Chemical

(4) U.S. Patent 2,033,934. Grebe, J. and S. M. Stoesser, "Dehumldifying Solution" Granted 3/17/36. Assigned to Dow Chemlcal Company

(5) U.S. Patent 1,992,177. 
Among the transitional metals, zinc salts have been uniquely Important. We will review these in Section 2-3.1.

We did a large number of semi-quantitative experiments in which very soluble salts were mixed with lithium. bromfde in various approximate mole ratios and then the vapor pressures of saturated solutions were measured over a short temperature interval.

\section{Added Salt}

Cadmium bromide

Nickel Nitrate

Iron (III) Bromide

Iron (III) Chloride

Sodium Chlorate

Sodium Nitrite

Sodium Bromide

Sodfum Thfocyanate

Sodium Iodide

Calcium Bromide ${ }^{(1)}$

Calcium Chloride

Manganese (II) Nitrate

Potassium Thiocyanate

Magnesium Chloride

Magnesium Bromide

Magnesium Iodide

Ammonium Chloride

Ammonium Nitrate

\section{Minimum?}

No

Yes, Smail

No

Yes, Small

No

No

No

No

No

Very Small

No

No

No

No

No

No

No

No

\section{Interaction Anticipated}

$\left[\mathrm{CdBr}_{4}\right]=$

$\left[\mathrm{NiBr}_{4}\right]=$

$\left[\mathrm{FeBr}_{4}\right]^{-}$

$\left[\mathrm{FeBr}_{4}\right]^{-}$

Strong Salt

Shot in Dark

Strong salt

Shot in Dark

Strong Salt

$\left[\mathrm{CaBr}_{4}\right]=$

$\left[\mathrm{CaCl}_{4}\right]=$

$\left[\mathrm{MnBr}_{4}\right]=$

Shot in Dark

Strong Salt

Very soluble material

Very Soluble

$\mathrm{NH}_{4}^{+}$. Ion Similar to $\mathrm{Rb}^{+}$

$\mathrm{NH}_{4}^{+}$Ion Similar to $\mathrm{Rb}^{+}$

(1) A ternary phase diagram (Blidin, V. P., "An Investigation of Solubility In Systems of $\mathrm{CaBr}_{2}\left(\mathrm{BaBr}_{2}\right)-\mathrm{LiBr}-\mathrm{H}_{2} \mathrm{O}^{\prime \prime}$ Collection of Articies on General Chemistry, 1, 88-96 (1953) in Russian) suggests that our minor gain in vapor pressure was smaller than should have been observed. The author points out, however, that the extreme viscosity of these systems makes the attainment of equilibrium extremely slow - perhaps our limited degree of interest was reflected in an inadequate number of days to. reach time equilibrium. 
Added Salt

Ammonium Blcarbonate

Ammonfum Thtocyanate

Amonium Bromide .

Caestum Bromide

Manganese Iodide

Iron (III) Thiocyanate
Minimum?

Yes, Slight

Yes, slight

Yes, Slight

Yes, S1Ight

Yes, Significant

No
Interaction Anticipated

$\mathrm{NH}_{4}^{+}$Ion Resemblance to $\mathrm{Rb}^{+}$ $\mathrm{NH}_{4}^{+}$Ion Resemblance to $\mathrm{Rb}^{+}$ $\mathrm{NH}_{4}^{+}$Ion Resemblance to $\mathrm{Rb}^{+}$ strong Salt

$\left[\min _{4}\right]=$

$\left[\mathrm{FeX}_{4}\right]^{-}$

\section{2-3.1 Zinc Halides}

Virtually every combination of 21 nc, calcium, lithium, chloride and bromide ions has been suggested for use in absorption refrigeration. Using vapor pressure of solutions as the sole criterion for evaluation of systems, many members of. this general group show great promise. The following short table, abstracted from a body of data collected by the Carrier Research Division, w111 illustrate some of the potential which these systems demonstrate.

\section{TABLE IV}

\section{SOLUBILITY/DEW POINTS ZINC AND CALCIUM CHLORIDES}

\begin{tabular}{lll} 
Solute Composition & $\begin{array}{l}\text { Volids, } 25^{\circ} \mathrm{C} \\
\text { Solidification }\end{array}$ & $\begin{array}{l}\text { apor Pressure } \\
\text { at } 43^{\circ} \mathrm{C} \mathrm{kPa}\end{array}$ \\
\hline
\end{tabular}

$\mathrm{L} 1 \mathrm{Br}$

$\mathrm{ZnCl}_{2}(\mathrm{n}=1)$

62.4

79.0

85.0

82.0

83.0

73.0
0.61

0.40

0.31

$0.6 \%$

0.37

0.33

where $n$ indicates mole fraction.

There is no denying the vapor pressure gains, over lithium bromide that are obtalnable with zinc based systems. What is also true is that these are very nasty solutlons to work with. Because of their very high viscosities (we have literally stood stirring rods up vertically in beakers of saturated solutions), they are very slow to reach any sort of equilibrium -- 
solublifty, vapor pressure, thermal -- and would have incredibly low heat transfer coefficients.

A second problem is hydrolysis: $\mathrm{Zn}^{++}+\mathrm{H}_{2} \mathrm{O} \longrightarrow \mathrm{Zn}(\mathrm{OH})^{+}+\mathrm{H}^{+}$ which renders these solutions highly acidic and very corrosive. Any attempts to adjust the acidity by adding hydroxides would merely further increase the viscosity by the formation of chainlike structures due to bridging hydfoxyl" coordination compounds which w111 be formed with zinc lons.

$\therefore$

Because of these limitations, the writer has firmly resisted any major investigations involving aqueous zinc salts.

A very complete study of the innumerable combinations possible among the lons under discussion was carried out by David Aronson (1) who. recites a multitude of solubility and vapor pressure data for ternary and quaternary systems.

(1) U.S. Patent 3,478,530 to David Aronson for "Absorption Refrigeration System," assigned to Worthington Corporation. Granted November 18, 1969. 


\section{3-0 REFRIGERANTS OTHER THAN WATER}

As pointed out earlier, there exist some potential refrigerants whose latent heats of evaporation, while lower than water, are significantly higher than those of the halocarbon refrigerants considered in the first volume of this report. Among these are:

$\begin{array}{lcc}\text { Refrigerant } & \Delta \mathrm{H}_{\mathrm{v}}\left(\mathrm{kJ} \mathrm{kg}^{-1}\right) \\ { } } & 1009.6 & \left(100^{\circ} \mathrm{C}\right) \\ \text { Ammonia } & 1372.0 & \left(-33^{\circ} \mathrm{C}\right) \\ \text { Methylamine } & 830^{\circ} & \left(-6^{\circ} \mathrm{C}\right) .\end{array}$

In addition to the loss of latent heat of vaporization, with its consequences assoctated with an increased pumping rate, some other disadvantages must also be considered. Primarlly, these are flammability, which leads to slgniflcant safety code problems, toxiclty and poorer heat transfer characteristics than with water based systems. These must be regarded as limitations rather than insurmountable obstacles.

\section{3-1 METHYL ALCOHOL - LITHIUM BROMIDE}

Vapor pressures of a few lithium bromide-methyl alcohol solutions were determined and the results, in the form of a family of Duhring plots, are presented in Figure 15.

A second series of solutions using lithium bromide and zinc bromide in a $2: 1$ mole ratio as the absorbent for a methanol system were also studled. The Duhring plots determined from the vapor pressure data are presented in Figure 16.

No detailed follow up to these systems was made even though the solubility-vapor pressure depression appeared to be more than adequate to support an air cooled system. The primary. reason for this was a series of film side heat transfer coefficient measurements done in the absorber simulation equipment. These results showed very low heat transfer in the 


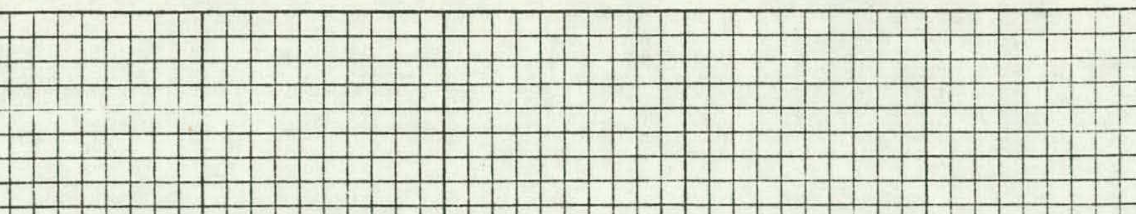

W

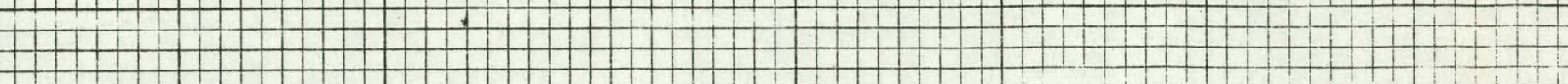

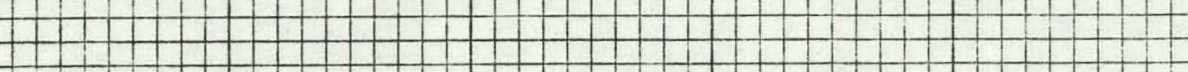

$7^{\circ}$

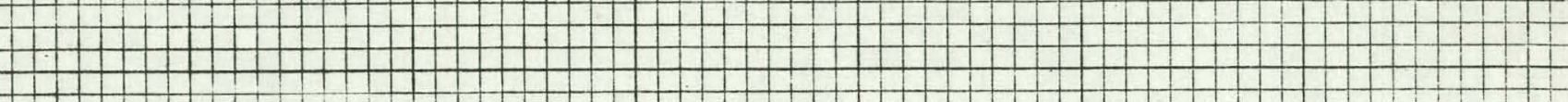

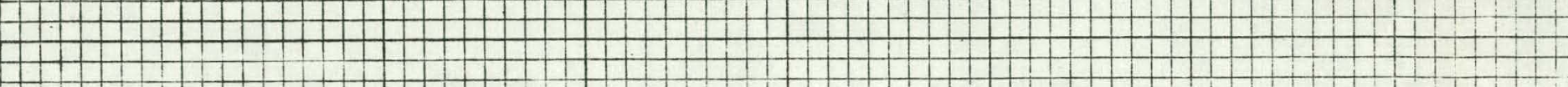

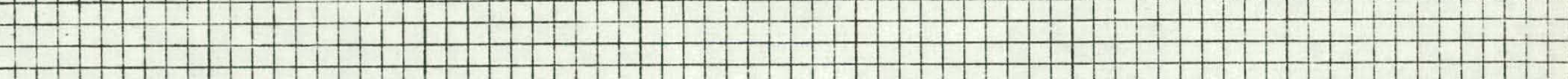

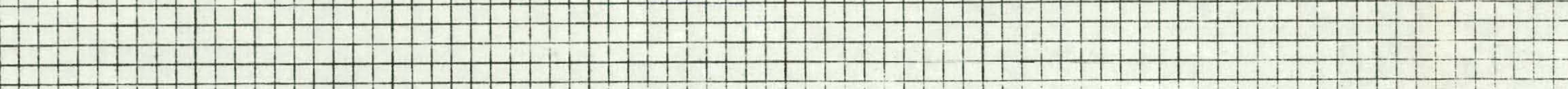

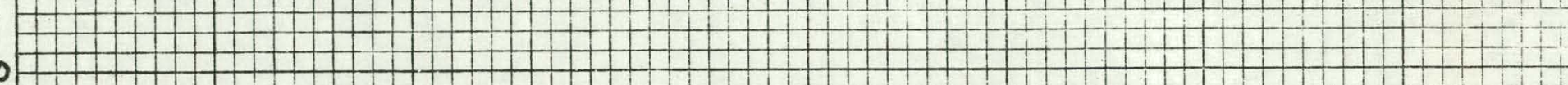

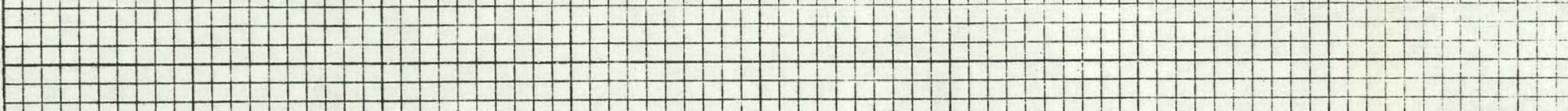

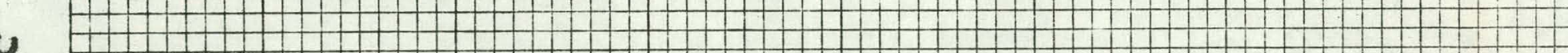

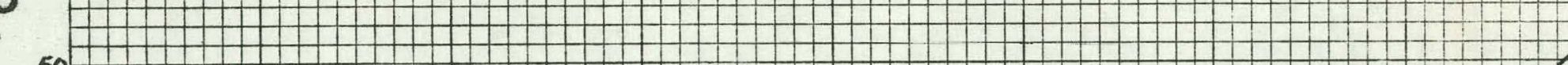

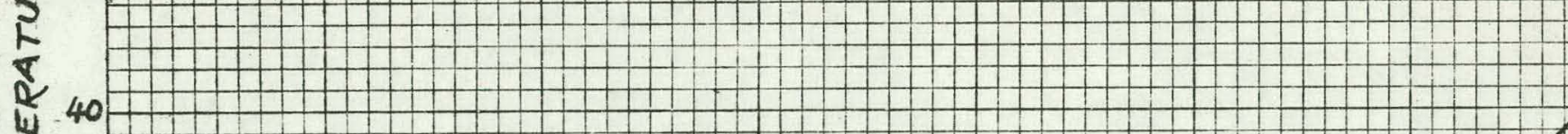

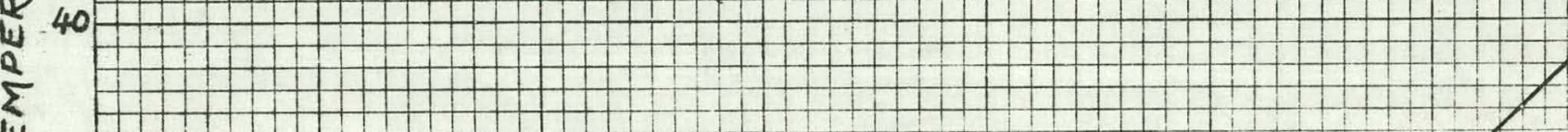

空

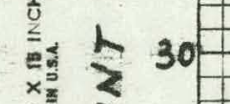

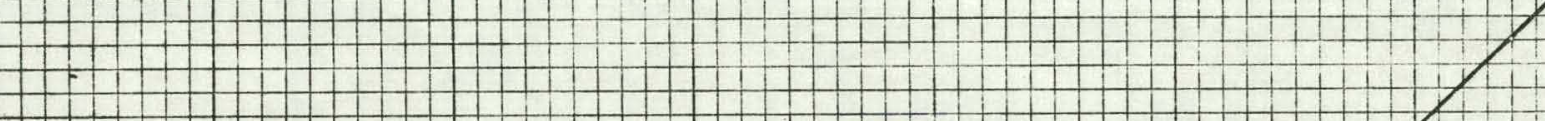

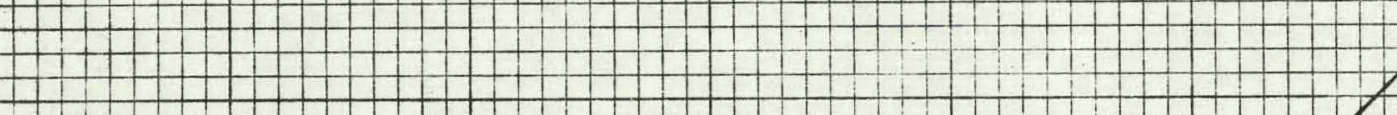

$\geq 3 0 \longdiv { 1 0 }$

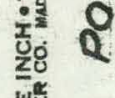

制

20

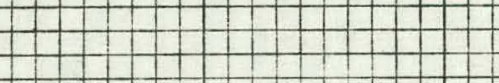

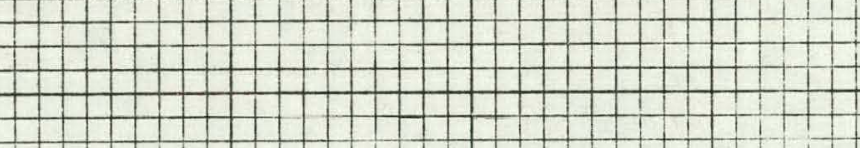

w

10

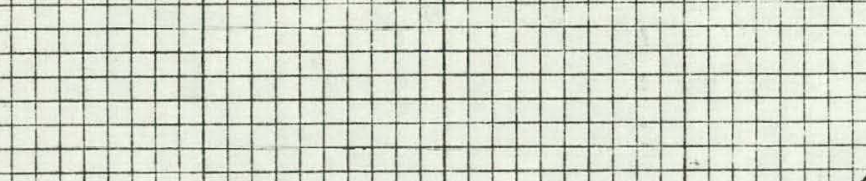

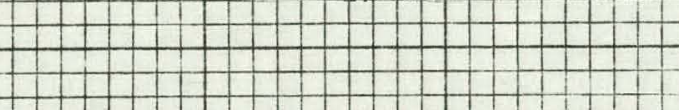
+1

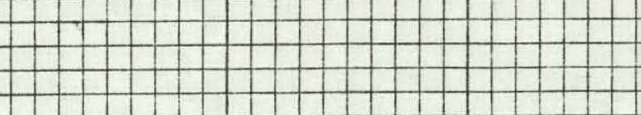

- $+2+2+1$

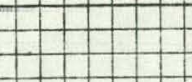

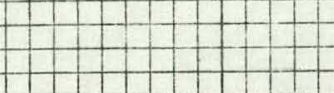

$-10$

10

20

30

50

60

SOLUTION TEMPERATURE

$+1+1$

$1>1$
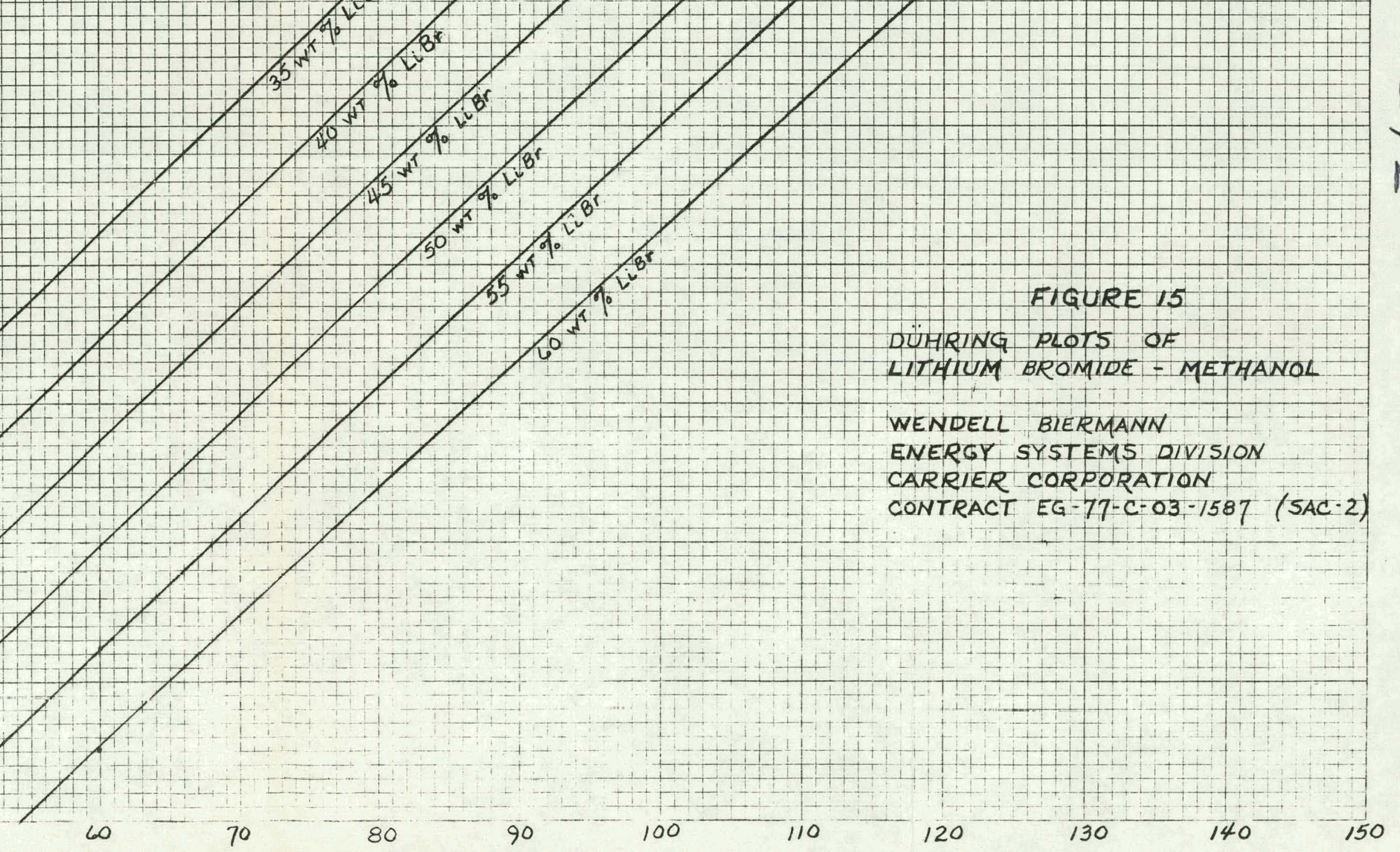
文

(10) I. W. + † +. H

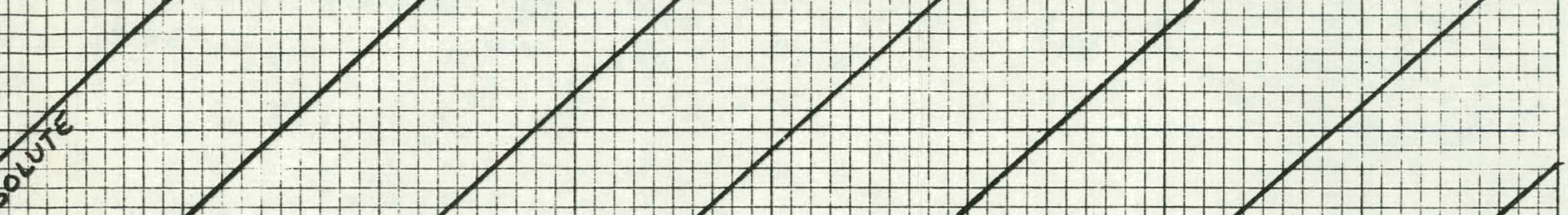

0

(3)

$\sum_{\substack{n \\ 0}}^{2}$

L

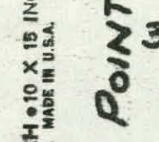

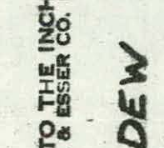

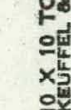

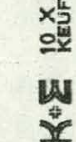

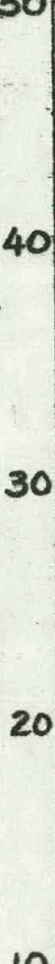

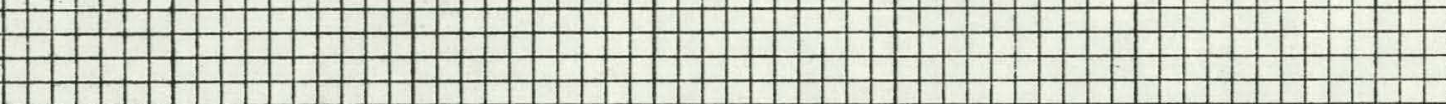

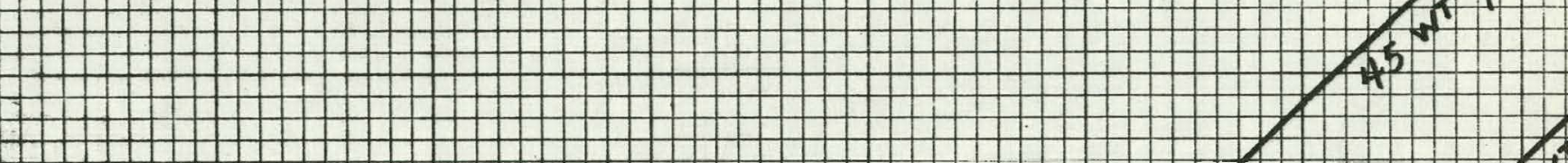

$1 / 5^{0^{5}}$

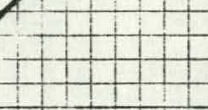

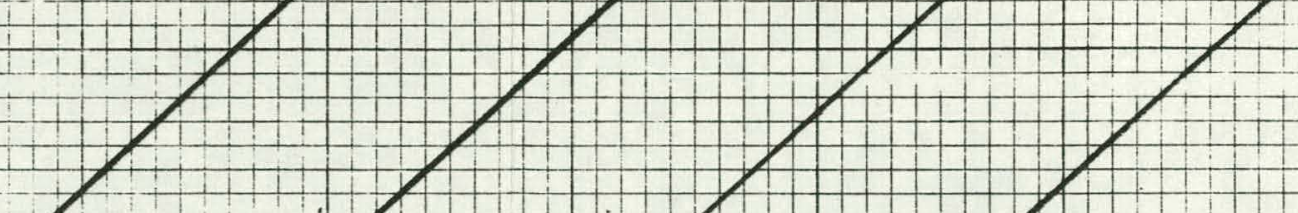

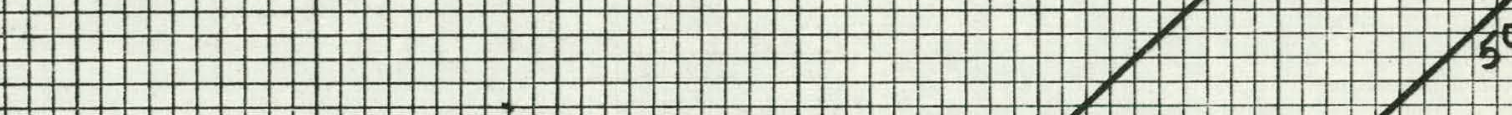

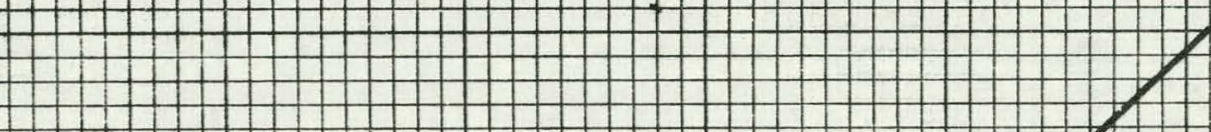
1

$/ s^{6}$ MI

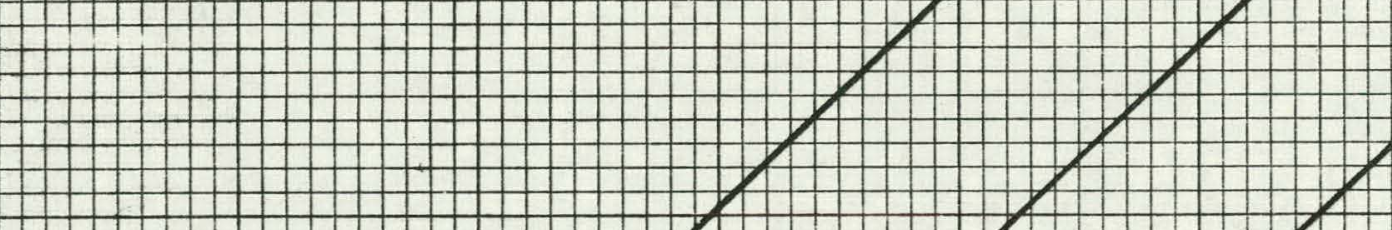

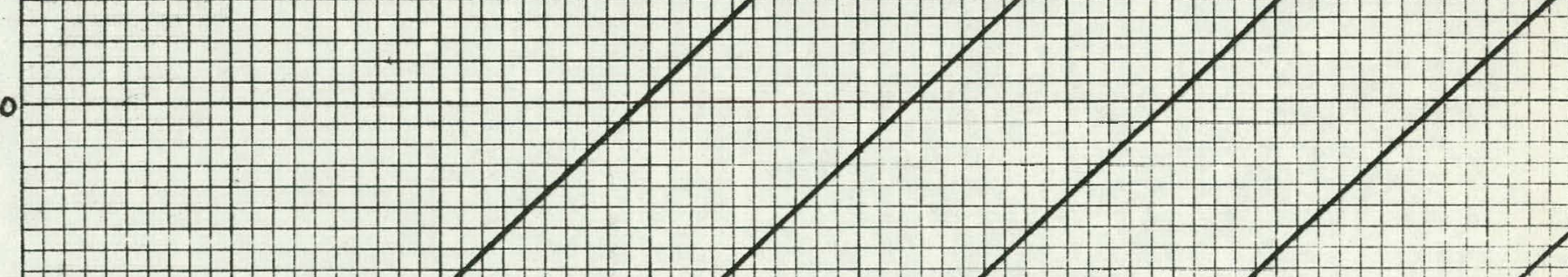

10 \begin{tabular}{l}
\hline+1 \\
\hline+1
\end{tabular}

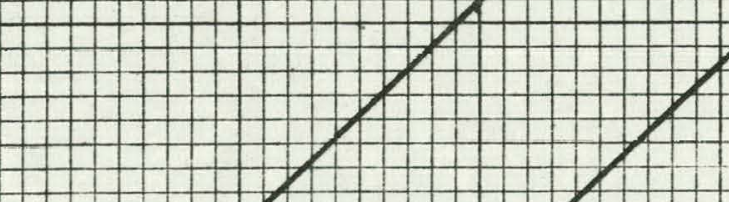

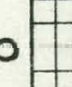

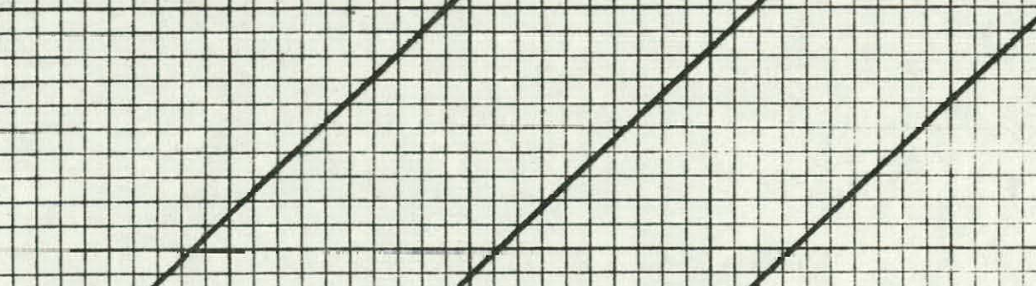
\begin{tabular}{|l|l|}
\hline 1 & 1 \\
\hline & 1
\end{tabular}

20 30 
falling film, which was interpreted as a high activation energy. to mass transfer from the vapor to the solution indicating the need for a heat transfer additive analogous to 2-ethyl hexanol in aqueous systems.

Since that time, the writer has had indications that this poor heat transfer rate might be in error and $1 \mathrm{t}$ is our intention to repeat these experiments in the course of the present program.

\section{3-2 AMMONIA AND METHYLAMINE AS REFRIGERANTS}

Ammonia has proved to be an excellent refrigerant in absorption cooling princfpally because it has a high latent heat of vaporization and because it is able to enter into strong associations, resulting in large negative deviations from Raoult's Law, with a variety of compounds which may be utilized as an absorbent. Methylamine 1s quite simflar to ammonia as shown in the following table in both physical properties and chemical behavior. Ammonta has a higher heat of vaporlzation; however, when used with water as an absorbent, methylamine has a greater concentration spread $(\sim 38 \%$ wt $)$ than ammonia $(\sim 25 \%$ wt) under similar operating conditions. The comparison of ammonia and methylamine as refrigerants is illustrated in Figure 17. It is our conclusion that there is little to choose between the two compounds as refrigerants.

For our experimentation, methylamine was preferred to ammonia because of the lower pressures involved and the greater flexibility the compound allowed in choosing absorbents among organic compounds. Being a stronger base than ammonia, methylamine would be expected to form stronger associations with actdic absorbents and, therefore, greater negative deviations from Raoult's Law and greater dew point depressions.

\section{Pliyelcal Properties of $\mathrm{NH}_{3}$ and $\mathrm{CH}_{3} \mathrm{NH}_{2}$}

$\begin{array}{lcc} & \frac{\mathrm{NH}}{3}_{3} & \frac{\mathrm{CH}}{3}_{2} \mathrm{NH}_{2} \\ \text { 1. Molecular Weight } & 17.03 & 31.06 \\ \text { 2. Boiling Point } & -33.35^{\circ} \mathrm{C} & -6.32^{\circ} \mathrm{C} \\ \text { 3. Critical Temperature } & 132.9^{\circ} \mathrm{C} & 156.9^{\circ} \mathrm{C} \\ \text { 4. Ionization Constant at } 25^{\circ} \mathrm{C} & . & \\ \quad\left(\times 10^{5}\right) & 1.8 & \sim 45 .\end{array}$


80

FIGURE 17

70

DÜHRING PLOTS FOR AMMONIA AND METHYLAMINE DISSOLVED IN WATER

SNERTY SYSTEMS DIYISION

CARRIER CORPORATION.

60

W. J. BIERMANN

CONTRACT EG-77-C.03-1587 (SAC-2)

$\therefore$

$\sum^{\circ}$

340

文30

10

○

.

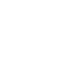

(
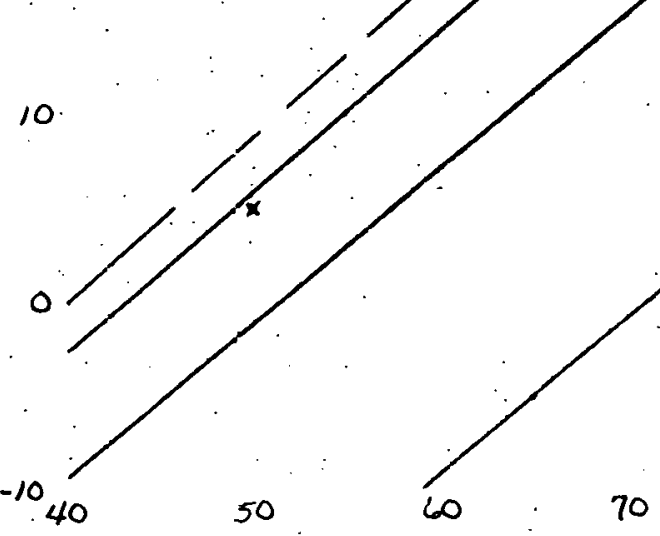

70

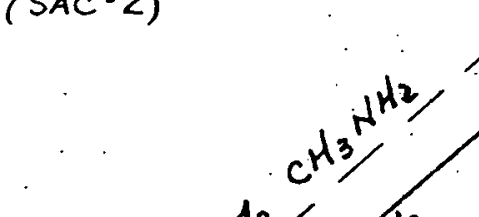




\section{3-2.1 Ammonia/Methylamine with Organic Absorbents}

Since methylamine is a strong organtc base, organic acids should be good absorbents. There are a very limited number of organic Lewis acids which have suitable physical properties, however, and our attention was focused on the protonic type; carboxylic actds, phenols, active hydrogencontaining compounds and hydroxy and mexcapto-compounds are some of the more common protonic organic actds.

Many salts of carboxylic acids are known to be thermally unstable (especially carboxylic ammonium salts) due to decarboxylation. This was found to be true for benzoic acid when mixed with methylamine; carbon dioxide was evolved at about $50^{\circ} \mathrm{C}$. For this reason carboxylic acids would not be suitable absorbents for methylamine.

Large dew point depressions were observed with solutions of methylamine and various phenols. However, the adducts of phenol and methylamine seemed to decompose at temperatures of about $150^{\circ} \mathrm{C}$. Th1s decomposition was noticed also with methyl p-hydroxybenzoate. The addition of water as a second absorbent had the effect of stabilizing the aminephenol adducts. Since the resulting ternary systems are quite simflar to the presently operated water-ammonia machine, no further exploration was done in this area. Some of the data obtained using phenols as absorbents for methylamine are given in Table $\mathrm{V}$.

Typical compounds containing active hydrogens include $\beta$-diketones, $\beta$-keto esters, 1mldes, acetylenes, etc. In these molecules, hydrogens are "active" because the presence of nelghboring electron-withdrawing groups makes them more protonic. Among the active hydrogen compounds, only the ... $\beta$-diketones and $\beta$-keto esters were examined. Since multiple bonds tend to undergo thermal catalytic polymerization, the acetylenes were not consldered. The 1mides, such as succinimide and phthalimide, are usually high melting solids which are not very soluble in methylamine and tend to decompose at moderace temperatures. Table VI gives vapor pressure data of methylamine and some organic esters with active hydrogens. The dew point depressions are generally good but unfortunately thelr thermal stabilities are all doubtful at temperatures above $150^{\circ} \mathrm{C}$, probably due to ammonolys 1 s or other types of thermal decomposition. 
Aliphatic polyhydroxy compounds appeared to be the most promising group among the binary organtc systems. Typlcal data for this group are shown in Table VII. The effectiveness of the OH group in association with methylamine can be demonstrated when comparing the vapor pressure dati of glycerol, trimethylene glycol, glycol and diethylene glycol solutions. It was found that on a mole basis, adding one more hydroxyl group to an aliphatic molecule would lower the vapor pressure to a degree which would more than compensate for the increase in molecular welght. An ether group was found to be less effective in assoclation with methylamine. 
TABLE V

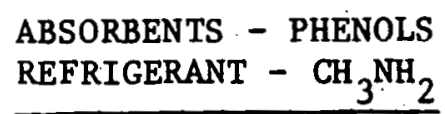

\begin{tabular}{|c|c|c|c|c|c|}
\hline Reaction & Absorbent & $\begin{array}{r}\text { Dew } \\
\text { at } \\
50^{\circ} \mathrm{C} \\
\end{array}$ & $\begin{array}{l}\text { Point Lor } \\
\text { Solution } \\
100^{\circ} \mathrm{C} \\
\end{array}$ & $\begin{array}{l}\text { ering } \\
\text { Temp. } \\
150^{\circ} \mathrm{C} \\
\end{array}$ & $\begin{array}{l}\text { Average Slope of } \\
\text { Duhring Line }\end{array}$ \\
\hline 1 & Phenol & & Unstable & & \\
\hline 2 & $\begin{array}{l}\text { p-oH Methyl Benzoate } \\
\text { wt } 15.7 \%\end{array}$ & & 105 & 117.5 & 0.64 . \\
\hline 3 & $\begin{array}{l}8 \% \text { Aq. Phenol Sol's } \\
\text { wt } 21.0 \%\end{array}$ & & (85) & 90 & \\
\hline 4 & 15\% Aq. Phenol Sol's & & & & . \\
\hline & A. wt $8.9 \%$ & & 99 & 102 & 0.93 \\
\hline & B. wt $16.0 \%$ & & 87 & 95 & 0.86 \\
\hline & C. wt $30.5 \%$ & 68 & 71 & .73 & 0.93 \\
\hline & D. wt $38.6 \%$ & 51.5 & 57 & 62 & 0.90 \\
\hline & E. wt $46.6 \%$ & 43.5 & 48.5 & & 0.90 \\
\hline & F. wt $50.3 \%$ & 37 & 43 & & 0.86 \\
\hline
\end{tabular}


TABLE VI

\begin{tabular}{c} 
ABSORBENTS - ORGANIC ESTERS WITH ACTIVE HYDROGEN \\
REFRIGERANT - $\mathrm{CH}_{3} \mathrm{NH}_{2}$ \\
\hline
\end{tabular}

9

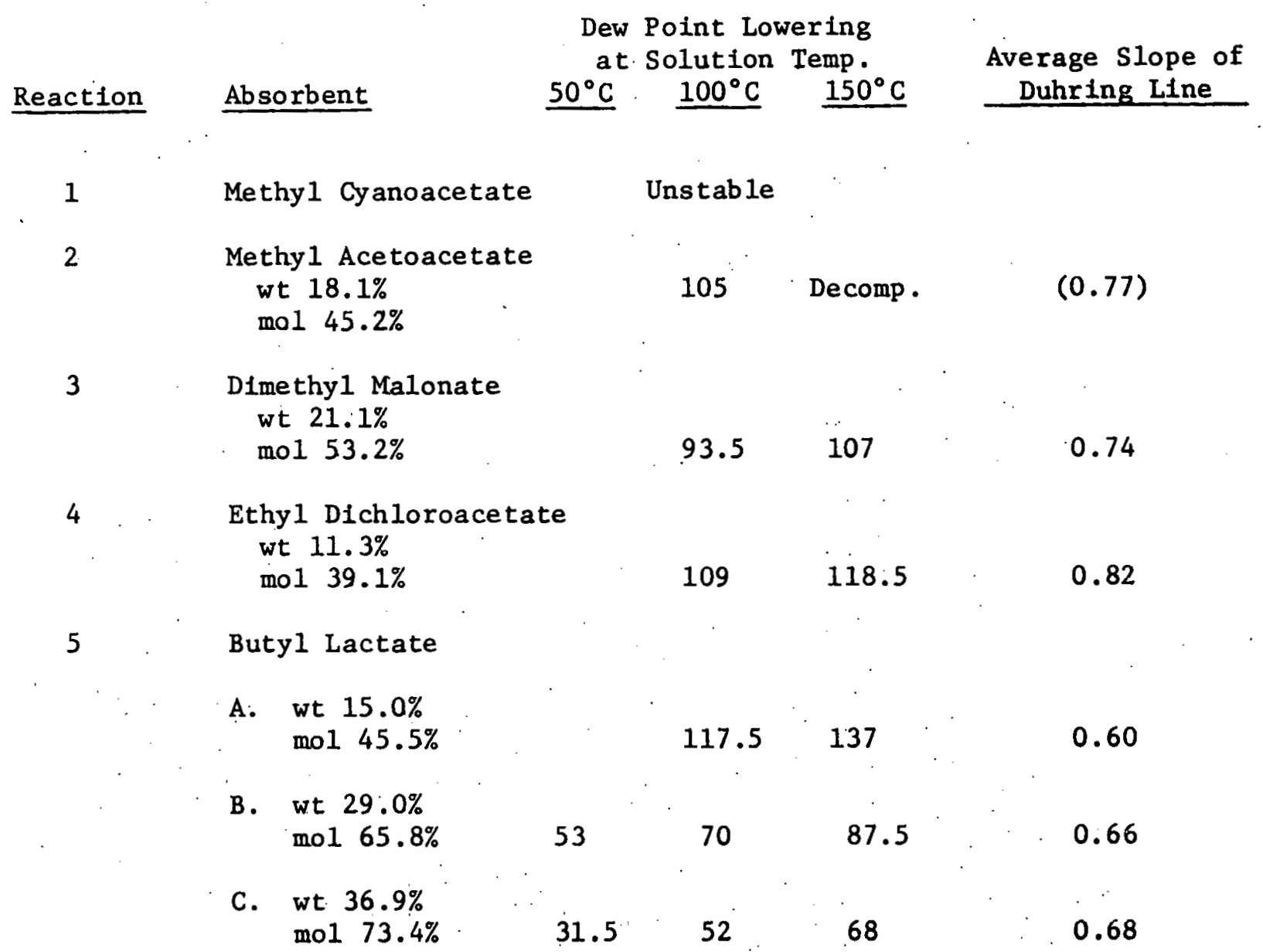


TABLE VII

ABSORBENTS - POLYHYDROXY COMPOUNDS

REFRIGERANT - $\mathrm{CH}_{3} \mathrm{NH}_{2}$

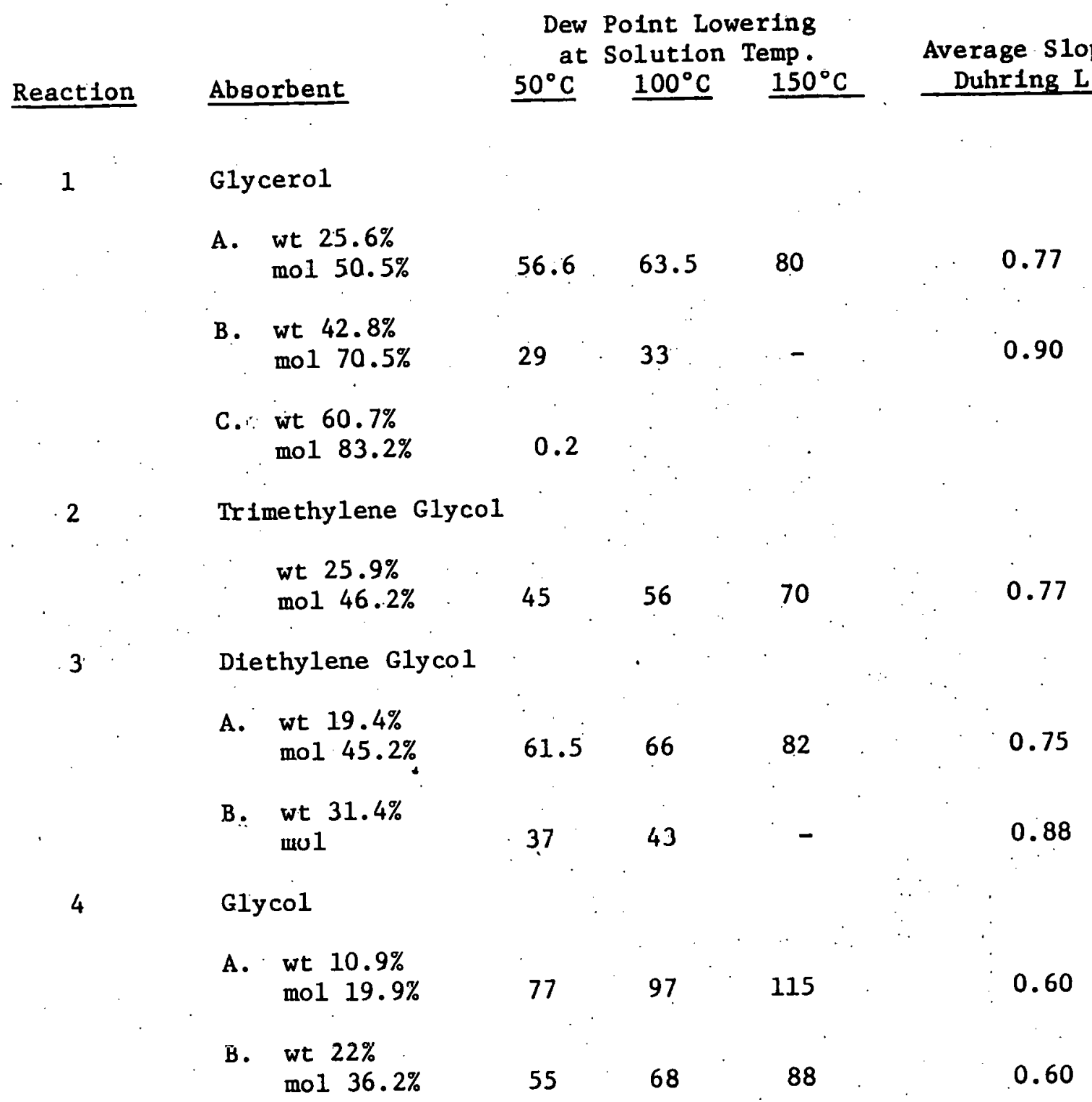




\section{3-2.2 Inorganic Salts as Absorbents for Methylamine}

The results obtalned by other researches indicated that metal salts in general are effective vapor pressure depressants for ammonia and methylamine. Our investigation was centered on the use of salts of alkali and transition metals as cations and chlorides, bromldes, lodides* and thiocyanates as anfons while avolding the unstable nitrates and chlorates and considerably less soluble alkaline earth salts. The results of the most promising systems are summarized in Tables VIII and IX.

The nature of the association between methylamine and metal salts is believed to be coordination of methylamine with the metal ions, and to a lesser extent from the interaction between methylamine and the pi-orbitals (if any) of the anionic group. Of the metal salts studied, 1ithium thiocyanate, which would be expected to coordinate very well with methylamine, proves to be the most soluble salt and the greatest vapor pressure depressant for methylamine.

Large negative deviations from Raoult's Law were observed with transition metal salts of thiocyanates and chlorides, but these were found to be the result of incompletely reversible reactions producing some metalamine complex salts relatively insoluble in methylamine. The results are plotted in Figure 18. Attempts to find a system employing a solvent to obtain complete reversibility proved futile.

* U.S. Patent 3,312,077 Absorption Refrigeration System tó W. L. McHale, et al., assigned to Robertshaw Controls. No data included. 


\section{TABLE VIII}

\section{METHYLAMINE AND HEAVY METAL THIOCYANATES}

Metal Wt. \% Temp. $\left({ }^{\circ} \mathrm{C}\right)$ at Vapor Pressure Thiocyanates $\mathrm{CH}_{3}$

\begin{tabular}{|c|c|c|c|c|c|c|c|c|c|c|c|c|}
\hline & 100 & & 13 & 19 & 25 & 30 & 35 & 38 & 42 & 46 & 50 & \\
\hline $\mathrm{Zn}\left(\mathrm{SCN}_{2}{ }_{2}\right.$ & 43.5 & & & & & & 30 & 33 & 36 & 38 & 44 & 48 \\
\hline \multirow[t]{2}{*}{$\operatorname{Ni}(\mathrm{SCN})_{\mathrm{x}}$} & 34.4 & 77 & 100 & 114 & 130 & 145 & & & & & & \\
\hline & 66.5 & & 9 & 21 & 27 & 33 & 37 & 40 & 46 & 48 & & \\
\hline \multirow[t]{3}{*}{$\mathrm{Co}(\mathrm{SCN})_{2}$} & 19.7 & 100 & 117 & 131 & 142 & 150 & 157 & & & & & \\
\hline & 31.6 & 85 & 95 & 106 & 115. & 120 & 127 & 133 & 138 & 143 & 147 & 152 \\
\hline & 37.0 & 65 & 77 & 88 & 97 & 104 & 110 & 117 & 122 & 127 & 131 & 135 \\
\hline \multirow[t]{4}{*}{ CuSCN } & 21.0 & & & & & & 128 & 133 & 141 & 146 & 152 & \\
\hline & 27.9 & & & & & & 108 & 115 & 121 & 128 & 133 & 139 \\
\hline & 34.9 & & & & & & 81 & 87 & 93 & 97 & 101 & 105 \\
\hline & 40.5 & & & & & & 63 & 70 & 74 & 78 & 82 & 86 \\
\hline \multirow[t]{2}{*}{$\mathrm{Cu}(\mathrm{SCN})_{2}$} & 39.2 & & & & & & 82 & 85 & 92 & 96 & 100 & 105 \\
\hline & 51.0 & & & & & & 50 & 54 & 57 & 61 & 64 & 68 \\
\hline
\end{tabular}

Dew Pt. Lowering of $\mathrm{CH}_{3} \mathrm{NH}_{2}$ at $100^{\circ} \mathrm{C}$

0
Negative
$89^{\circ} \mathrm{C}$
$5^{\circ} \mathrm{C}$
$100^{\circ} \mathrm{C}$
$85^{\circ} \mathrm{C}$
$73^{\circ} \mathrm{C}$
$81^{\circ} \mathrm{C}$
$70^{\circ} \mathrm{C}$
$52^{\circ} \mathrm{C}$
$36^{\circ} \mathrm{C}$
$50^{\circ} \mathrm{C}$
$15^{\circ} \mathrm{C}$




\section{TABLE IX}

METHYLAMINE AND ALKALI METAL THIOCYANATES

Metal Wt. \% Temp. at Vapor Pressure, ${ }^{\circ} \mathrm{C}$

\begin{tabular}{|c|c|c|c|c|c|c|c|c|c|c|c|c|}
\hline & 100.0 & & 13 & 19 & 25 & 30 & 35 & 38 & 42 & 46 & 50 & \\
\hline \multirow[t]{3}{*}{ Nasca } & 50.0 & 50 & 60 & 67 & 75 & 82 & 87 & 91 & 95 & & & \\
\hline & 61.1 & 27 & 36 & 43 & 50 & 55 & 60 & 64 & 68 & 72 & & \\
\hline & 68.1 & 15 & 24 & 32 & 38 & 44 & 48 & 53 & 58 & 62 & 65 & \\
\hline \multirow[t]{3}{*}{ LiSCN } & $48: 2$ & 94 & 105 & 114 & 122 & 130 & 135. & 142 & & & & \\
\hline & 54.3 & & 81 & 88 & 95 & 102 & 107 & 114 & 119 & 124 & 129 & 134 \\
\hline & 63.0 & & 50 & 57 & 63 & 68 & 73 & 79 & 83 & 88 & 93 & 96 \\
\hline \multirow{3}{*}{$\left.\begin{array}{ll}80 \% & \text { NasCN } \\
20 \% & \text { LiSCN }\end{array}\right\}$} & 30.6 & 66 & 78 & 87 & 97 & 106 & 113 & 122 & 128 & 136 & & \\
\hline & 42.8 & 54 & 66 & 74 & 82 & 89 & 95 & 101. & 106 & 111 & & \\
\hline & 53.4 & 39 & 50 & 58 & 65 & 72 & 78 & 84 & 89 & 93 & 97 & \\
\hline \multirow[t]{4}{*}{$\left.\begin{array}{ll}62 \% & \text { NaSCN } \\
38 \% & \text { LISCN }\end{array}\right\}$} & 26.4 & 100 & 112 & 122 & 132 & 141 & 148 & & & & & \\
\hline & 42.1 & 72 & 82 & 91 & 100 & 107 & 114 & 120 & 125 & 131 & & \\
\hline & 49.3 & 64 & 73 & 82 & 88 & 95 & 101 & 106 & 110 & 116 & & \\
\hline & 54.3 & 48 & 58 & 67 & 72 & 79 & 84 & 89 & 94 & $98^{\circ}$ & 102 & \\
\hline
\end{tabular}

Dew Pt. Lowering

of $\mathrm{CH}_{3} \mathrm{NH}_{2}$ at $100^{\circ} \mathrm{C}$

0

$51.0^{\circ} \mathrm{C}$

$21.0^{\circ} \mathrm{C}$

$14.0^{\circ} \mathrm{C}$

$92.0^{\circ} \mathrm{C}$

$71.5^{\circ} \mathrm{C}$

$43.5^{\circ} \mathrm{C}$

$73.0^{\circ} \mathrm{C}$

$61.5^{\circ} \mathrm{C}$

$48.0^{\circ} \mathrm{C}$

$95.0^{\circ} \mathrm{C}$

$75.0^{\circ} \mathrm{C}$

$66.0^{\circ} \mathrm{C}$

$52.5^{\circ} \mathrm{C}$ 


$$
\begin{array}{r}
-\mathrm{CH}_{3} \mathrm{NH}_{2} \\
-\mathrm{CH}_{3} \mathrm{NH}_{2} \text { IN } \mathrm{ZN}(\mathrm{SCN})_{2} \\
\square--\mathrm{CH}_{3} \mathrm{NH}_{2} \text { IN } \mathrm{CUSCN} \\
\nabla-\mathrm{CH}_{3} \mathrm{NH}_{2} \text { IN } \mathrm{Cu}(\mathrm{SCN})_{2} \\
\square--\mathrm{CH}_{3} \mathrm{NH}_{2} \text { IN } \mathrm{Ni}(\mathrm{SCN})_{x} \\
-\mathrm{CH}_{3} \mathrm{NH}_{2} \text { IN } \mathrm{CO}(\mathrm{SCN})_{2} \\
\mathrm{OR} \mathrm{CO}(\mathrm{SCN})_{2} \cdot 3 \mathrm{H}_{2} \mathrm{O}
\end{array}
$$$$
-54-
$$

10,000

\section{0}

8000

7000

\section{0}

5000

ฉ̊ 尺ै

4000

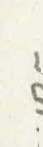

?

$$
3000
$$

\& 2500

2000

1500

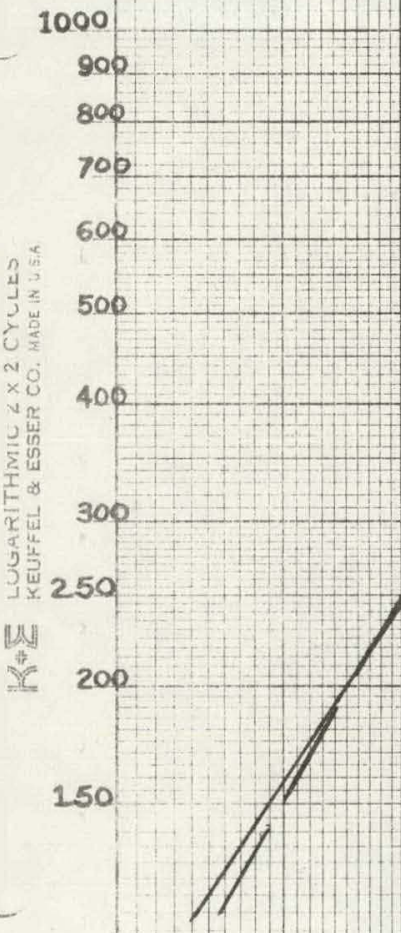

100

$$
\begin{array}{llll}
15 & 20 & 25 & 30
\end{array}
$$$$
40
$$

FIGURE 18

TRANSITIONAL METAL THIOCYANATES in methYLAMINE
CARRIER CORPORATION

ENERGY SYSTEMS DIVISION W. J. BIERMANN

CONTRACT EG-77-C-03-1587 (SAC-2) 
Figure 19 presents a series of Duhring plots for sodium thiocyanate and methylamine along with the crystallization limits. For the standard air cooled conditions we have adapted for screening purposes, we find that the strong solution ( $107^{\circ} \mathrm{C}$ solution temperature, $47^{\circ} \mathrm{C}$ dew point) would be $51.7 \%$ LISCN and the weak solution $\left(47^{\circ} \mathrm{C}\right.$ solution, $7^{\circ} \mathrm{C}$ dew point) $46.0 \% \mathrm{NaSCN}$. This is a usable concentration spread, but unfortunately skirts so close to saturation that the cycle would probably be highly prone to crystallization.

Lithium thiocyanate, with a room temperature solubility of about 52 weight percent appeared to be a very favorable candidate for an air cooled absorption system with methylamine. A major qualification program was undertaken between the Institute of Gas Technology and the Research Division of Carrier Corporation. Figure 20 presents a Duhring plot based on data determined during this program.*

Based on these Duhring plots, one projects a concentration spread of $39.75 \%$ to $36.85 \%$ under our provisional air cooled rating curves, and a safe $12 \%$ displacement of the strong solution from the crystallization line.

The lithium thiocyanate program was terminated following the observation that a reaction took place, at an easily measurable rate, between copper or iron surfaces and the lithium thiocyanate-methylamine solution. This observation was made in carefully dried solutions.

Figure 21 shows some unsmoothed vapor pressure data, presented in Duhring plot form, for two lithium thiocyanate solutions in ammonia. The vapor pressure depressions are similar to those observed for methylamine but the absolute pressure would, of course, be much higher. No stability studies were made but there is no reason to expect sufficient stability improvement over methylamine to permit successful system operation.

* Macriss, R. A., Punwani, D., Rush, W. F., and Biermann, W. J., "Thermodynamic and Physical Properties of Monomethylamine-Lithium Thiocyanate System," J. Chem. Eng. Data 15, 466 (19/U). 
$-56-$

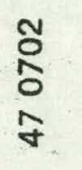

\section{0}

\begin{tabular}{|l|l|l|l|l|}
\hline \hline+14 & & \\
\hline
\end{tabular} + H.

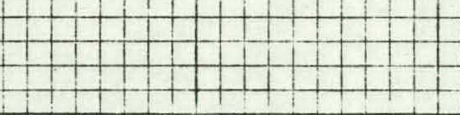

H+11

60

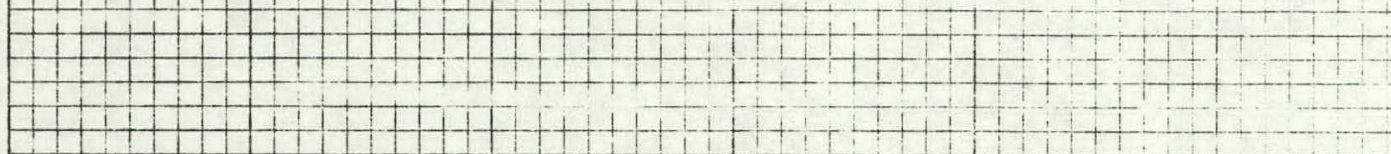

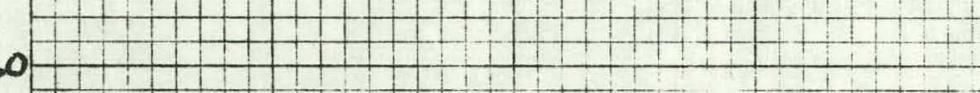

50

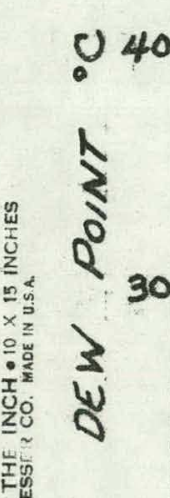

20

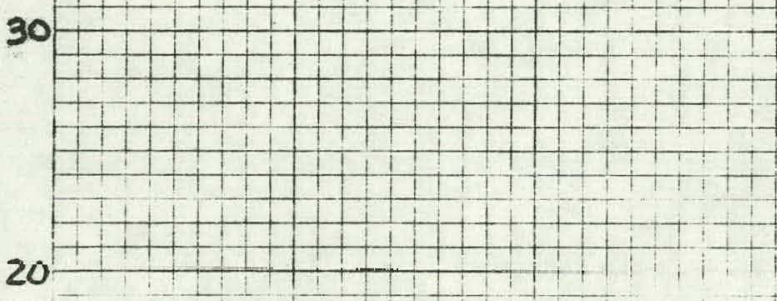

过

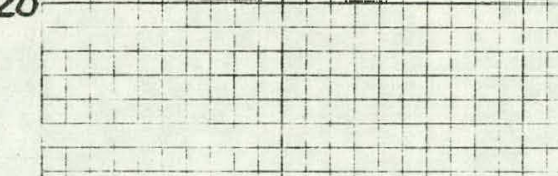

10

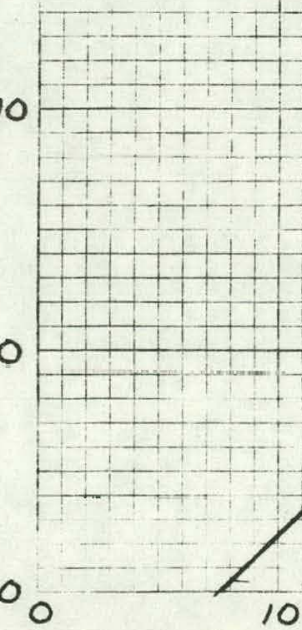

-10 。

20

30

140

50

$\begin{array}{ccc}60 & 70 & 80 \\ \text { SOLUTION TEMPERATURE UC } & 90\end{array}$

100

140 


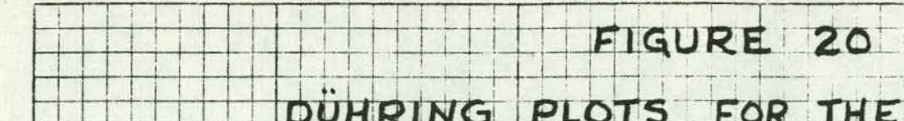 \\ DÜHRING PLOTS FOR THE SYSTEM \\ HIIITHUM THIOCYANATE - METHYLAMINE \\ BO ENERGY SYSTEMS DIVISION
CARRIER CORPORATION \\ W. J. BIERMANN \\ CONTRACT EG-77-C-03-1587 (SAC-2)}

$707+\ldots$

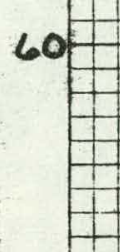

$e^{50}$

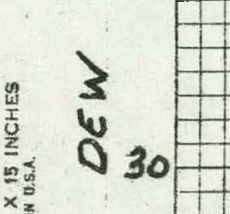

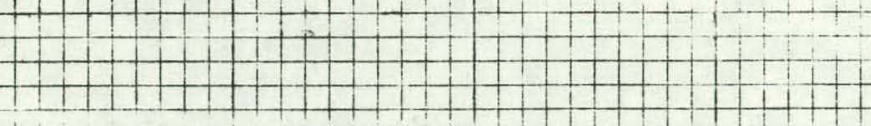

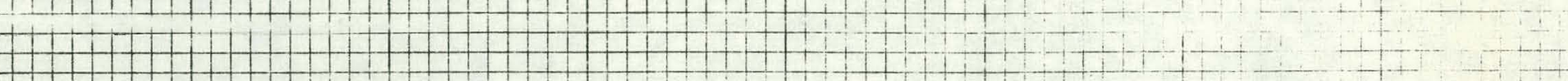

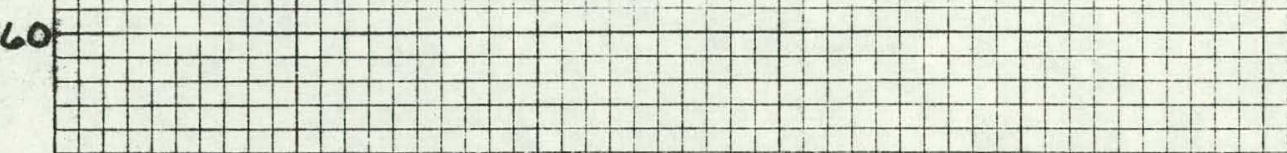

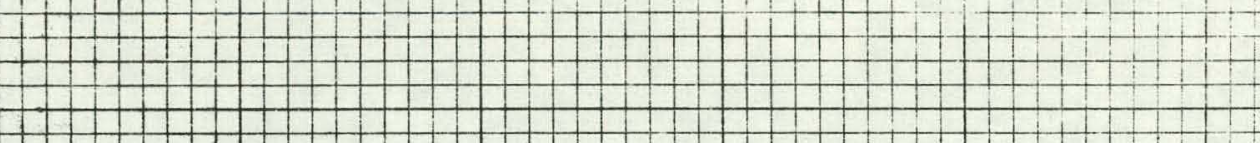

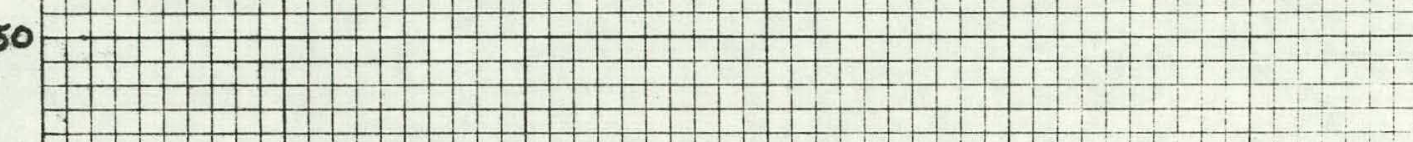

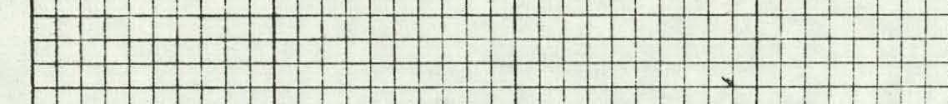
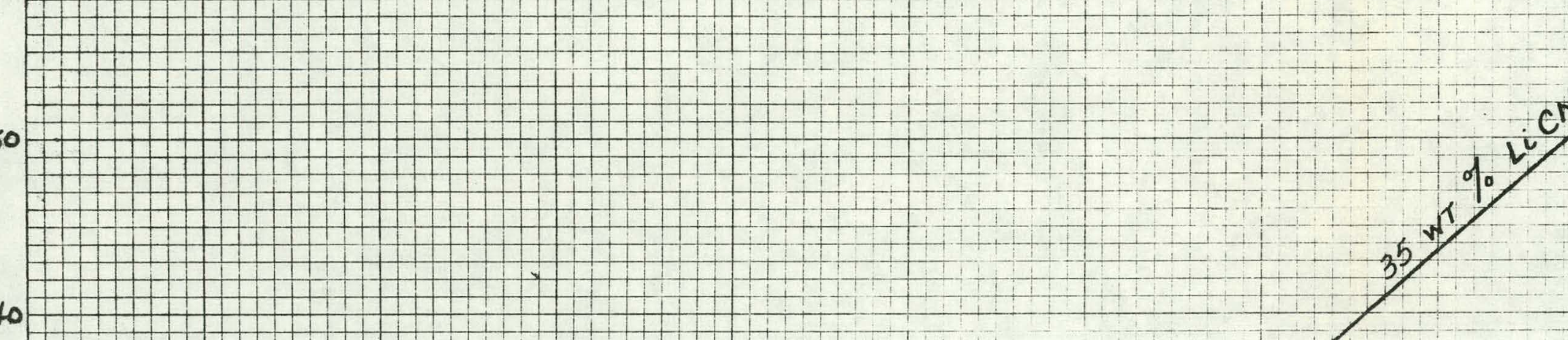

cr/

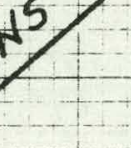

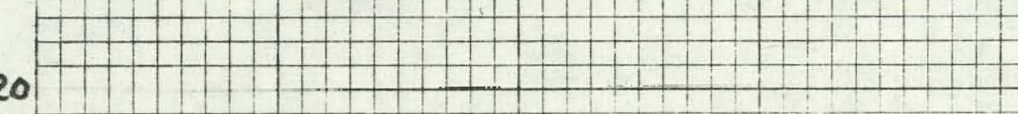

10

$\circ$

40

temperature 


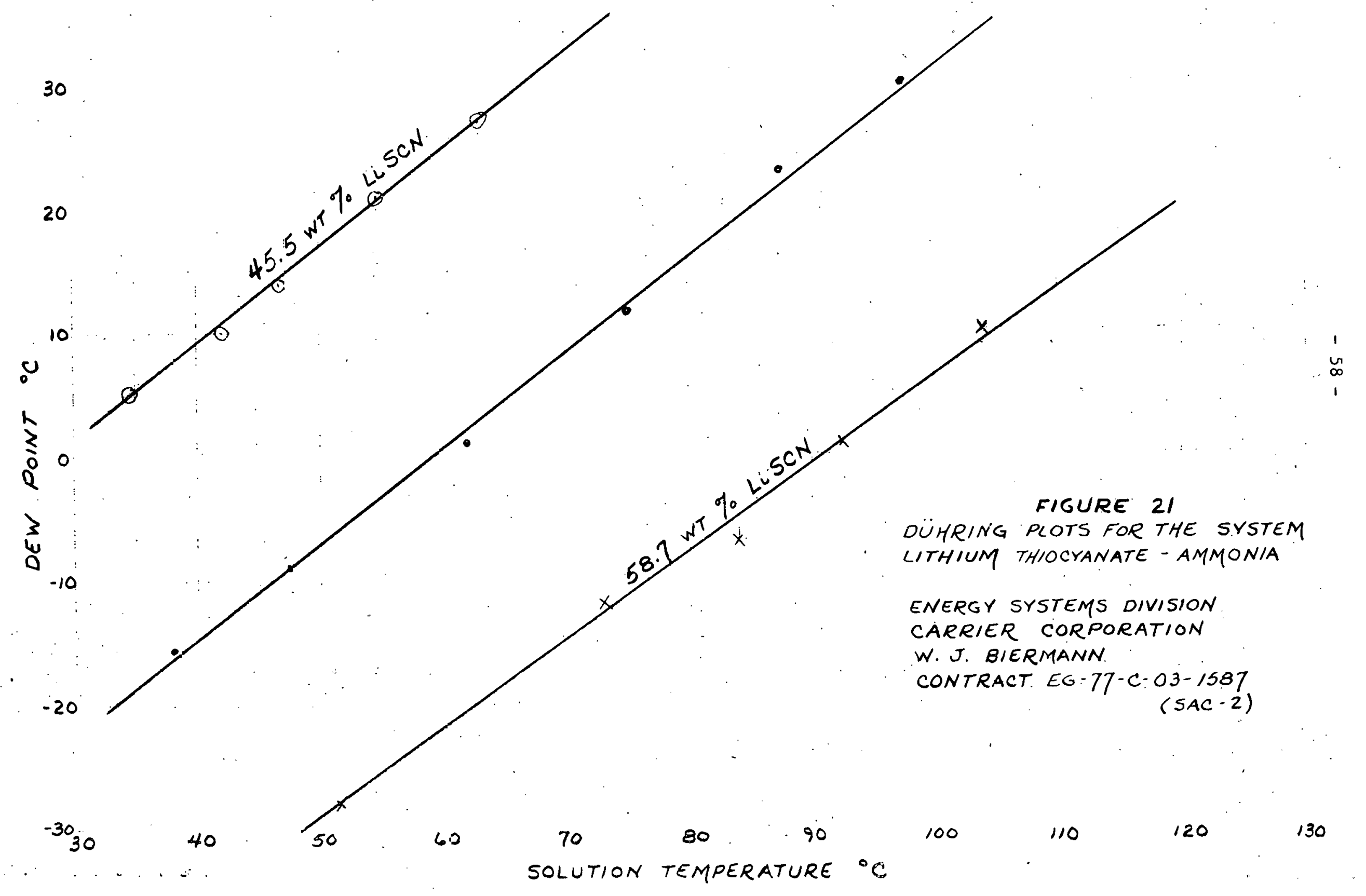




\section{3-2.3 Ternary Refrigerant-Absorbent Combinations}

\section{3-2.3.1 Two Inorganic Salts}

The large vapor pressure depression effect of lithium thiocyanate and its high solubility in methylamine appeared to make the methylaminelithium thfocyanate pair an attractive absorption refrigeration system. This system, however, has the disadvantage of being viscous and having a small concentration spread (see 3-2.2). Therefore, sodium thiocyanate was utilized as a viscosity reducing diluent. Our results indicated that for this $\left(\mathrm{CH}_{3} \mathrm{NH}_{2}-\mathrm{LiSCN}-\mathrm{NaSCN}\right)$ ternary system, the optimum ratio of LiSCN to NaSCN should be approximately 4:6 in weight. For such a solution, the concentration spread is improved; the solution is clear and comparatively nonviscous, but further investigation would almost certainly disclose chemical instability with metals of construction.

\section{3-2.3.2 With Two Organic Compounds}

Mixtures of two types of organic compounds have been tested as absorbents for methylamine. The purpose was to see the effect of the third component on the solubility of the main absorbent and on the concentration spread. Combinations such as methylamine-phenol-glycol and methylamine hydroquinone-dimethylformamide have been examined. The results indicate no advantage or improvement over binary organic systems.

\section{3-2.3.3 Inorganic Salts and Organic Solvents*}

The above Investigations show that for methylamine:

A. The organic absorbents give very poor dew point depressions with moderate concentration spreads .

B. Alkali metal salts of halides or pseudohalldes are good dew point depressants, but yield small concentration spreads.

C. Mixtures of two alkali metal salts glve both good dew point depression and improved concentration spreads.

* U.S. Patent - 1,734,278, Refrigerant to J. G. Tandberg, Ässigned to Electrolux Servel. 
Therefore, 1t was declded to use high bolling organic solvents as a third component in an attempt to increase the concentration spread of the methylamine-alkall salt system, hoping to retain the magnitude of the dew point depression. The hypothesis is that if a polar organic solvent is a good coordination agent, it would compete with methylamine in solvating the alkali metal ion. An equilibrium would then be established such that at low methylamine concentrations the equilibrium would favor the metal-ionsolvent complex formation. At high methylamine concentration, formation of a methylamine-metal ion complex would be favored according to the mass action law. The concentration spread should be increased if the above premise is correct. The results of our first experiments with methylaminelithium thiocyanate-tetraethylene glycol dimethyl ether proved that the expected dew point depression and increased concentration spread.was obtainable. Because of this result an extensive investigation was performed in the following directions.

\section{3-2.3.3.1 Solvent Effect}

Different high bolling organic solvents were tested.with methylamine and lithium thiocyanate in order to determine the effect of solvent polarity, dielectric constant, and functional groups. When $37.5 \%$ LiSCN and $62.5 \%$ of each of several solvents were used as absorbents for methylamine, the following concentration spreads were obtalned: (Reference Conditions for this section: $150^{\circ} \mathrm{C}$ generator, $47^{\circ} \mathrm{C}$ condenser and absorber, $6^{\circ} \mathrm{C}$ evaporator).

Tetraethylene glycol dimethy1 etlier Diethylene glycol

1, 4-butanediol

2-aminoe thano1

$\mathrm{N}, \mathrm{N}$-dimethy1 formamide

irimethyl glycol

Ethylene glycol
22 we \% (19-41) of methylamine 18 wt \% (37-19) " 20 wt \% $(40-20)$

12 wt \% (14-26) " 12 wt \% ".

21 wt \% (42-21) . "

18 w. \% $(36-18)$ iा 
The Duhring plot of $\mathrm{CH}_{3} \mathrm{NH}_{2}-\mathrm{LiSCN}$-tetraethylene glycol dimethyl ether 18 given in Figure 22 as a typical example. In Figure 23 the results are plotted in the form of Raoult's Law plot at $100^{\circ} \mathrm{C}$. In this plot the design condition corresponds to a pressure range from 40 to 100 psia. One can see that the system with tetraethylene glycol. dimethyl ether has the flattest curve across this range. This is consistent with its largest concentration spread in the group.

\section{3-2.3.3.2 Concentration Effect}

The relative concentrations of the components in $\mathrm{CH}_{3} \mathrm{NH}_{2}-\mathrm{LiSCN}-$ solvent system can affect the change in concentration spread, as one would expect. When lithium thiocyanate was mixed with different amounts of tetramethylene glycol dimethyl ether, the following methylamine concentration spreads were obtalned under reference conditions:

Weight Ratio
Ether/LiSCN
0.83

1.25

1.67

11.7
Wt \% Conc. Spread $\left(\mathrm{CH}_{3} \mathrm{NH}_{2}\right)$ $16(42-26)$

$16(38-22)$

$22(41-19)$

$11(25-14)$

Simflar results with other solvents are:

Weight Ratio

2-aminoethano1/L1SCN

0.67

Wt \% Conc. Spread $\left(\mathrm{CH}_{3} \mathrm{NH}_{2}\right)$

1.67

$22(39-17)$

$12(26-14)$

Dimethyl Formamide/LiSCN.

0.67

$18(11-23)$

1.67

12

The above data indicate that:

1. For the ether as solvent, the optimum welght ratio of TEGDM ether to Iithium thiocyanate is approximately 1.25 . 


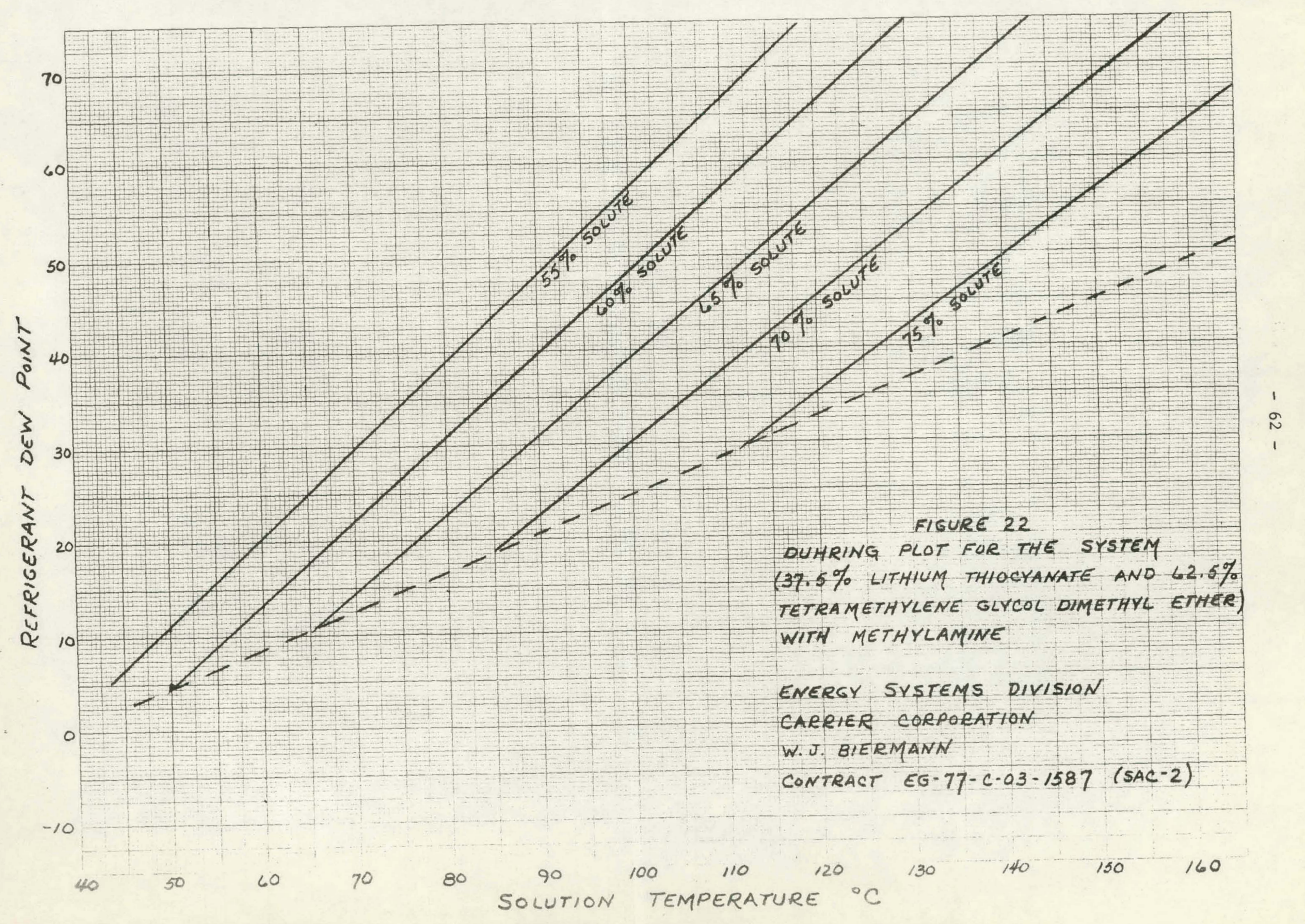




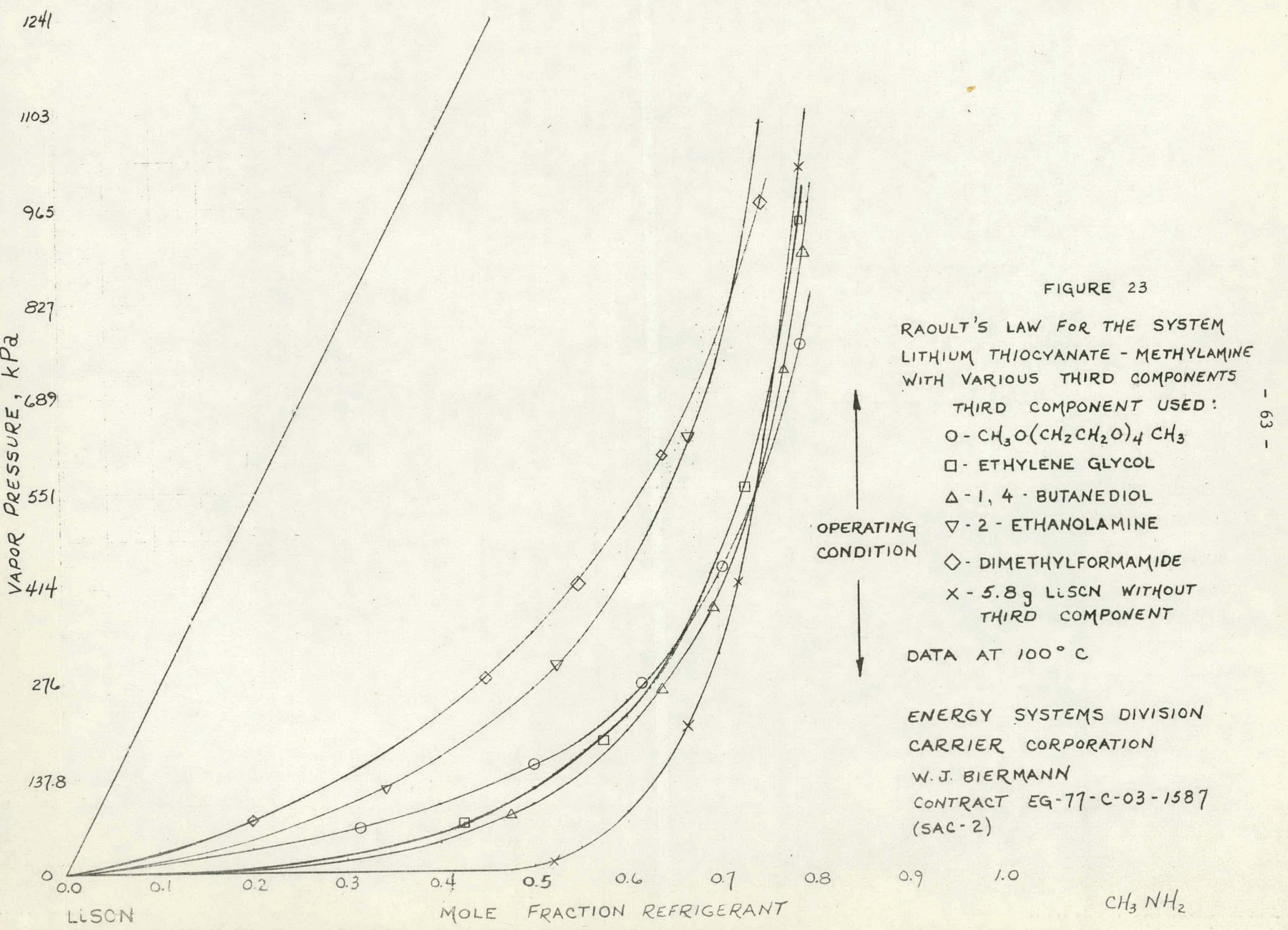


2. For solvents of smaller molecules, such as 2-aminoethanol or dimethyl formamide, a smaller amount of solvent is required to achleve the optimum concentration spread. In terms of mole fraction or functionality (the number of functional groups in the solvent), the ratio of LiSCN to solvent is somewhat constant for solutions of largest concentration spreads. The effect can also be explained in terms of the Raoult's Law plot as shown in Figure 24.

\section{3-2.3.3.3 Anionic Effect}

When $37.5 \%$ of $\mathrm{LiBr}$ and $62.5 \%$ of tetraethylene glycol dimethy 1 ether was tested as an absorbent, a methylamine concentration spread of 20 wt \% was obtained. This is similar to the result with LiSCN as salt. But the range of concentration spread being 34-14 in comparison with 41-19 for LiSCN as salt, indicates loss of some dew point depression. This is consistent with the fact that the LiBr formula weight is greater than LiSCN.

$37.5 \% \mathrm{LiCl}$ and $62.5 \% \mathrm{H}_{2} \mathrm{O}$ was tested as absorbent for methylamine. A 21 wt \% (38-17) concentration spread was obtained. Water was used in this case because of the expected low solubility of LiCl in methylamine. Comparing this system with the above system, it is interesting to note that although such a large mole fraction of water was present, the dew point depression was still greater.

\section{3-3 METHYLAMINE/AMMONIA, CONCLUSIONS}

In a paper on "Vapor Pressure of Ammonia and Methylamine in Solutions for Absorption Refrigeration Systems," published by J. P. Robertson in ASHRAE (1966), the conclusion was reached that the use of ammonia in an absorption system using a nonaqueous absorbent appeared quite promising. The following systems were cited:

1. Ammonia and sodium thiocyanate

2. Ammonia and a mixture of sodium thincyanate and iodide

3. Ammonia and a mixture of sodium thiocyanate and 1,4-butanediol. 


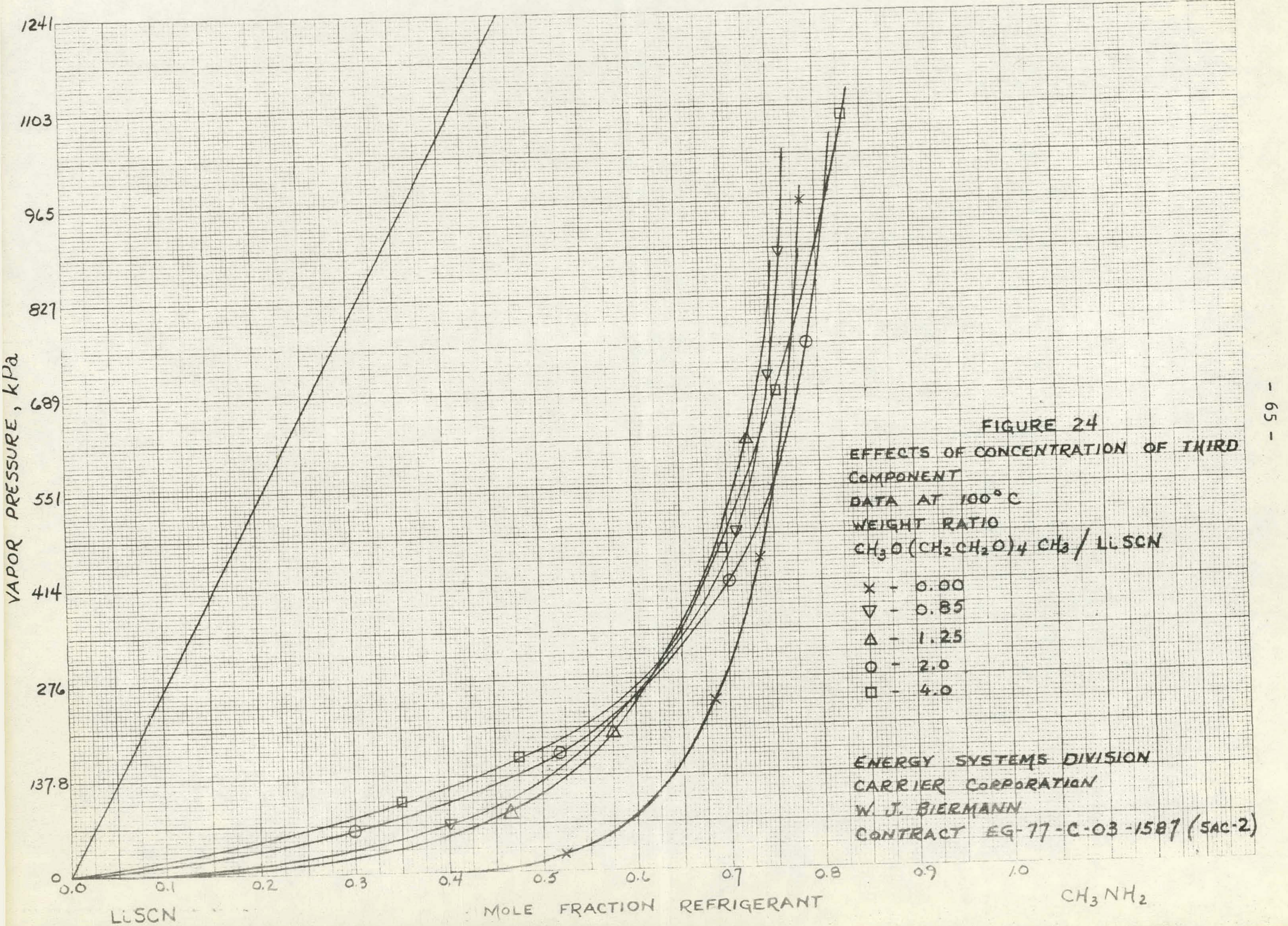


The Carrier work described here has led us to conclude that sodium thlocyanate is not quite soluble enough to support an air cooled absorption cycle. The work clted does suggest that an "antifreeze additive" could be found which would permlt the construction of such a machine based on methylamine or amonia, with sodium thlocyanate and one of several antifreeze additives. Because of the several disadvantages (codes, latent heat, heat transfer properties) of ammonla and methylamine as compared to water, it appeared more advantageous to follow up by developing a water-salt-antifreeze system Instead.

The exploratory work done with lithium thiocyanate indicated that this material would be a very promising material to develop with methylamine, particularly in some of the mixtures. The chemical instability with regard to containment materials, discovered only after considerable effort had been expended in glass containers or with only short time exposures to metal, makes any further efforts with lithium thiocyanate too high a risk to justify any efforts, in the writer's fudgment. 


\section{4-0 CONCLUSIONS AND RECOMMENDATIONS}

In the search area described in this volume, Part II - Solid Absorbents, High Latent Heat Refrigerants, we have Identified three systems which could be used for developing an air cooled, solar driven, absorption machine.

A. Lithlum chlorate/lithium bromide-water with an amine heat transfer additive. The system has, in its favor, sufficient thermodynamic information to justify optimism regarding its thermodynamic and heat transfer suitability for this application. The two major disadvantages are the limitations on materials of construction and the lack of commercial availability of lithium chlorate.

This system is a viable alternate, should our present antifreeze additive candidate system prove to have some unforeseen obstacle.

B. The possible use of lithium bromide and methyl alcohol will be re-examined as another possible alternate.

C. Ammonia/methylamine with lithium thiocyanate. (perhaps 1ithium bromide) and an anti-crystallization additive could be developed. Our concerns with this system are the long term stability of the thiocyanate ion in the environment obtaining in an absorption machine and the limitations involved in using a refrigerant which is both flammable and toxic. 
$\because 8$

Carrier Energy Systems Division

\section{Carrier Corporation}

Carrier Tower

P. O. Box 1000

Syracuse, New York 13201 